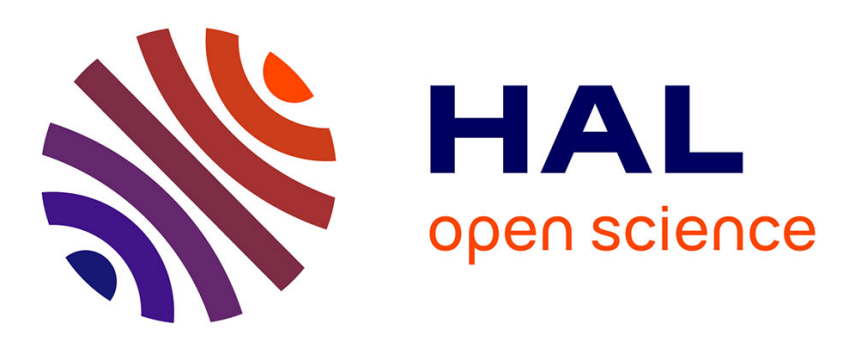

\title{
Fatigue damage mechanisms of short fiber reinforced PA66 as observed by in-situ synchrotron X-ray microtomography
}

Helloise Rolland, Nicolas Saintier, Ilan Raphael, Nicolas Lenoir, Andrew King, Gilles Robert

\section{To cite this version:}

Helloise Rolland, Nicolas Saintier, Ilan Raphael, Nicolas Lenoir, Andrew King, et al.. Fatigue damage mechanisms of short fiber reinforced PA66 as observed by in-situ synchrotron X-ray microtomography. Composites Part B: Engineering, 2018, 143, pp.217-229. 10.1016/j.compositesb.2017.12.051 . hal02279832

\section{HAL Id: hal-02279832 \\ https://hal.science/hal-02279832}

Submitted on 5 Sep 2019

HAL is a multi-disciplinary open access archive for the deposit and dissemination of scientific research documents, whether they are published or not. The documents may come from teaching and research institutions in France or abroad, or from public or private research centers.
L'archive ouverte pluridisciplinaire HAL, est destinée au dépôt et à la diffusion de documents scientifiques de niveau recherche, publiés ou non, émanant des établissements d'enseignement et de recherche français ou étrangers, des laboratoires publics ou privés. 
archives-ouvertes

\section{Fatigue damage mechanisms of short fiber reinforced PA66 as observed by in-situ synchrotron X-ray microtomography}

Helloise Rolland, Nicolas Saintier, Ilan Raphael, Nicolas Lenoir, Andrew King, Gilles Robert

\section{To cite this version:}

Helloise Rolland, Nicolas Saintier, Ilan Raphael, Nicolas Lenoir, Andrew King, et al.. Fatigue damage mechanisms of short fiber reinforced PA66 as observed by in-situ synchrotron X-ray microtomography. Composites Part B: Engineering, Elsevier, 2018, 143, pp.217-229. hal-02279832

\section{HAL Id: hal-02279832 \\ https://hal.archives-ouvertes.fr/hal-02279832}

Submitted on 5 Sep 2019

HAL is a multi-disciplinary open access archive for the deposit and dissemination of scientific research documents, whether they are published or not. The documents may come from teaching and research institutions in France or abroad, or from public or private research centers.
L'archive ouverte pluridisciplinaire HAL, est destinée au dépôt et à la diffusion de documents scientifiques de niveau recherche, publiés ou non, émanant des établissements d'enseignement et de recherche français ou étrangers, des laboratoires publics ou privés. 


\title{
Fatigue damage mechanisms of short fiber reinforced PA66 as observed by in-situ synchrotron X-ray microtomography
}

\author{
H. Rolland ${ }^{\mathrm{a}}$, N. Saintier ${ }^{\mathrm{a}, *}$, I. Raphael ${ }^{\mathrm{a}, \mathrm{d}}$, N. Lenoir ${ }^{\mathrm{b}}$, A. King ${ }^{\mathrm{c}}$, G. Robert $^{\mathrm{d}}$ \\ a Arts et Métiers ParisTech, CNRS, I2M Bordeaux, Esplanade des Arts et Métiers, F-33405 Talence Cedex, France \\ b PLACAMAT, UMS 3626, Avenue Docteur Albert Schweitzer, 33608, Pessac, France \\ ' Synchrotron Soleil, Psyche beamline, L'Orme des Merisiers, 91190, Saint Aubin, France \\ d Solvay Engineering Plastics, Avenue Ramboz, BP 64, 69192, Saint-Fons, France
}

\section{A R T I C L E I N F O}

\section{Keywords:}

Fatigue

Damage mechanisms

Polyamide

Microtomography testing

3D observations

\begin{abstract}
A B S T R A C T
The understanding of fatigue damage mechanisms of short fiber reinforced thermoplastics are a key issue in order to optimize material processing and propose physically based multiscale fatigue damage models. The presented work aims at a fine description of 3D damage development as observed by synchrotron X-ray microtomography. Damage processes at the micro and mesoscale are fully described in order to extract the elementary damage mechanisms, their sequence and kinetics. The effects of local fiber configuration and orientation are particularly detailed. From observations it is clearly evidenced that cavitation plays a major role in the fatigue damage process as it triggers all elementary damage mechanisms observed at the microscale. It is also shown that a characteristic length appears in the fatigue damage development. This internal length is in the order of magnitude of the spherulite size, suggesting a strong impact of the spherulite size on the fatigue damage development. Finally the effect of local fiber orientation on the micro and meso crack orientation is presented.
\end{abstract}

\section{Introduction}

Short glass fiber reinforced (SGFR) thermoplastics are materials with a good ratio between density and mechanical performances. For this reason they represent an interest to be used in the automotive field, for instance, where the reduction of the vehicles weight is one priority. In order to optimize the design of parts, the fatigue behaviour of the materials has to be understood and modelled. SGFR thermoplastics are mainly moulded by injection which is a well-suited process for industrial production. Indeed, it allows short process cycles, high dimensional precision and complex shapes. However, during the injection step, the matrix flow field leads to heterogeneous orientations of fibers. The resulting microstructure is generally characterized by distinguishable layers; resulting in a so called core-shell-skin structure.

The effect of fiber orientation on the fatigue behaviour of SGFR thermoplastics has been studied at the specimen scale [1,2] and at a microscopic scale. For instance, Bernasconi [3] determined the anisotropy of the material at the local scale, from the analysis of local orientation of fibers. The effect of fiber orientation on damage mechanism has also been investigated in the literature. Lang et al. [4] observed failure surfaces of specimens and deduced fatigue failure mechanisms from them, as Horst and Spoormaker [5,6]. The authors took into account the fiber orientation in their scenario, but could not consider the damage kinetics during the fatigue test nor the damage distribution in the bulk of the material. Tanaka et al. [9] investigated the effect of fiber orientation on the crack propagation, form fractography analysis and scanning electron microscopy (SEM) observations. In a receent study Belmonte et al. [8] presented a description of the crack paths of fatigue cracks initiated from sharp notches and associated mechanisms higlighting the role of fiber failure or damage at fiber end from surface SEM observations. However none of these works were able to clearly observe the progressive evolution of damage.

To study the behaviour and the damage mechanisms of these materials with a complex microstructure, 3D observation tools are more and more employed. The development of X-ray microtomography, in particular, allows to reach high resolution observation of the bulk material. This technique is more and more used to evaluate bulk damage in composite materials under diffreent kind of loadings (see for example Tan et al. [10] for dynamic loadings or Sola et al. [11] for fatigue damage on laminate composite). In the case of SGFR thermoplastics, Cosmi and Bernasconi [12] evaluate the volume of damage in specimens tested at different percentages of their expected lifetime. In similar materials, Arif et al. [13,14], to characterize the damage mechanisms in this type of material.

\footnotetext{
* Corresponding author.

E-mail address: nicolas.saintier@ensam.eu (N. Saintier).
} 
Previous works of the authors $[15,16]$ showed that in situ microtomography testing allowed the high resolution 3D monitoring of damage evolution in the bulk of the material under quasi-static loadings. Based on this approach, in situ microtomography fatigue tests were performed to identify the damage mechanisms of short glass fiber reinforced polyamide 6,6 . In order to study the effect of fiber orientation on damage mechanisms, specimens have been extracted following different orientations compared to the main flow direction. To the authors knowledge, this paper presents the firsts 3D in situ observations of bulk damage evolution in SGFR polyamide under fatigue loading.

\section{Experimental procedure}

\subsection{X-ray microtomography}

Experiments presented in this work were performed on Psyche beam-line at the Soleil Synchrotron (Saclay, France). The set-up parameters used for the experiments are described below. The filtered X-ray beam ( $2 \mathrm{mrad}$ mirror, $0.5 \mathrm{~mm}$ aluminum and $0.25 \mathrm{~mm}$ silver) had an energy of about $26 \mathrm{keV}$. The CMOS detector with $6.5 \mu \mathrm{m}$ pixels, was associated to a $\times 10$ objective, leading to a voxel edge size of $0.65 \mu \mathrm{m}$, on the acquired image. Specimen-sensor distance was $35 \mathrm{~mm} .1500$ projections were recorded per scan during a $180^{\circ}$ rotation of around $5 \mathrm{~min}$, with 31 references pictures before and after scanning.

\subsection{In-situ microtomogrpahy compact fatigue machine}

A machine was developed to test specimens by fatigue loading and to enable X-ray microtomography measurements. The machine has been designed to be compact, in order to minimize the distance between the specimen and the sensor. To maximize the X-ray beam signal, the machine had to present an homogeneous path around the specimen with a minimum attenuation of the X-ray beam. This function is ensured by a $2 \mathrm{~mm}$ thickness PMMA tube at the level of the specimen gage length (cf. Fig. 1(b)). The machine was directly mounted on the rotating stage of the beam line, as shown on Fig. 1. A load sensor measures the load applied to the specimen. All tests were performed under load control, with a maximal capacity of $1.5 \mathrm{kN}$.

\subsection{Specimen preparation, geometry and conditioning}

The material is a Technyl ${ }^{\circ} \mathrm{A} 218 \mathrm{~V} 30$, a commercial grade of polyamide 6,6 reinforced by $30 \mathrm{wt} \%$ of short glass fiber, supplied by Solvay Engineering Plastics-France. Specimens are obtained from rectangular plates with a $3.24 \mathrm{~mm}$ thickness, obtained by injection moulding. The injection moulding process leads to an heterogeneous orientation of fibers in the thickness of the plates. This structure is usually described as a superposition of distinguishable layers: the skin, the shell and the core. In our case the core (resp. shell) has a thickness of $0.3 \mathrm{~mm}$ (resp. $1.4 \mathrm{~mm}$ ), the core layer being located at mid-thikness of the plate. The skin exhibits a pseudo random orientation of fibers while fibers in the shell (resp. in the core) part have an orientation which is, in average, close to the injection flow (resp. orthogonal to the injection flow). See Ref. [16] for further details.

In order to describe the effect of fiber orientation on the damage mechanisms and the effect of the anisotropy of the identified core-shellskin structure on its development, samples were extracted following three different orientations with respect to the main injection direction: $0^{\circ}, 45^{\circ}$ and $90^{\circ}$.

The geometry of the specimen was designed to accommodate the constrains of the experimental set-up. Indeed, 3D X-ray microtomography only allows to observe relatively small volumes, depending on resolution and sensor size. The synchrotron experimental set-up described in the previous section allows to obtain a cylindrical observed zone of $1.33 \mathrm{~mm}$ diameter and $1.33 \mathrm{~mm}$ height $(2048$ pixels $\times 0.65 \mu \mathrm{m}$ voxel edge size). The gage length was designed so that the stress state in the observed volume was homogeneous. A square section was chosen to improve microtomography quality (compared to a rectangular section). Taking into account these elements, the geometry of the specimen was chosen as presented in Fig. 2. This geometry allows to obtain similar

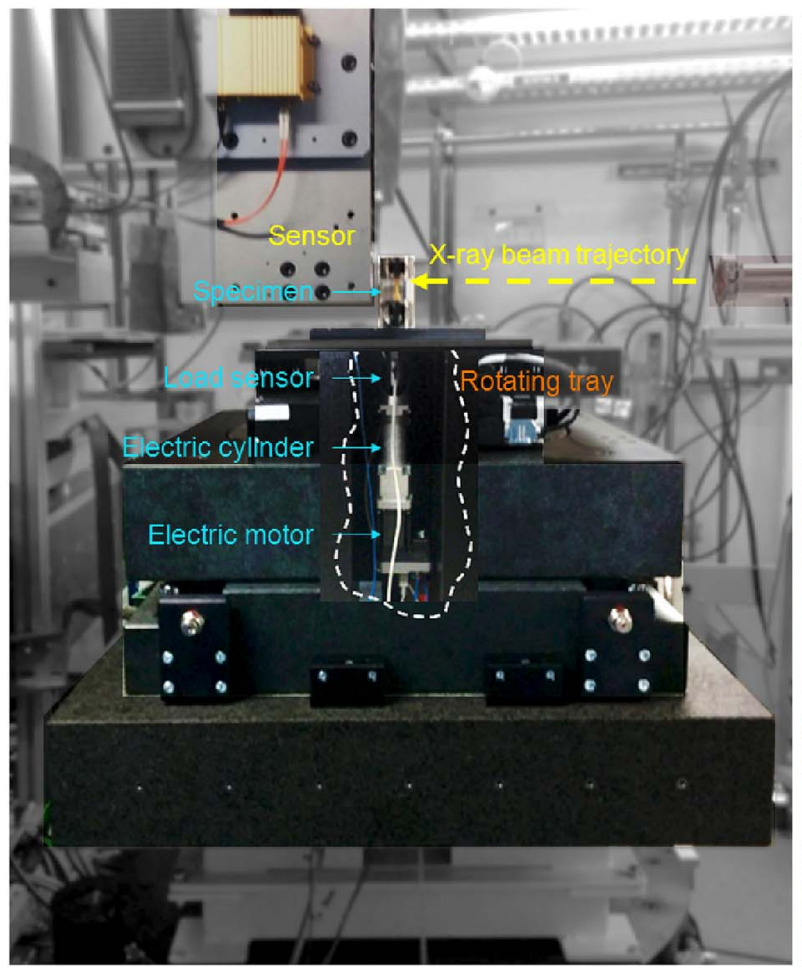

(a) Machine description

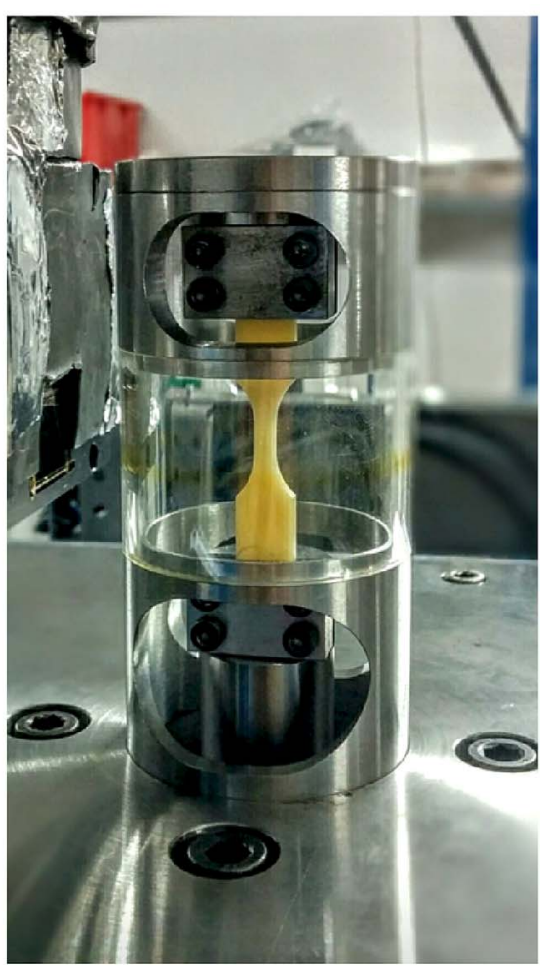

(b) Compact upper part of the machine

Fig. 1. Compact fatigue machine set up for in situ testing on the Psyche beam-line. 


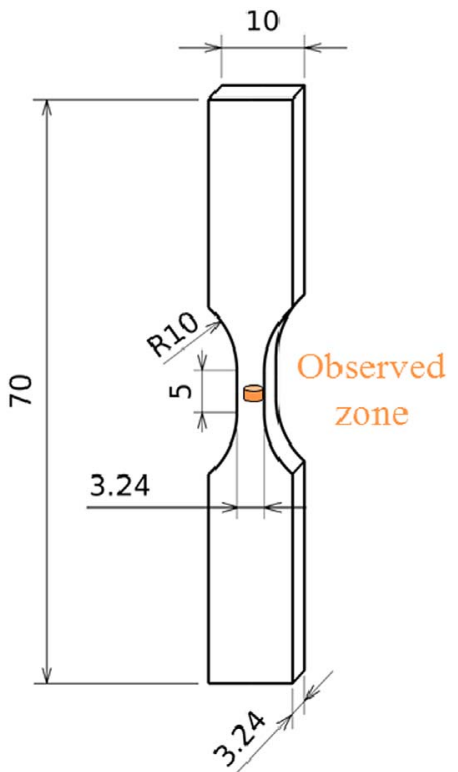

Fig. 2. Specimen geometry for in situ fatigue tests.

Table 1

Microtomography scans combined with fatigue testing, short lifetime range - RH50 specimens $-R=0.1, f=3 \mathrm{~Hz}$.

\begin{tabular}{llll}
\hline Specimen & $0^{\circ}$ & $45^{\circ}$ & $90^{\circ}$ \\
\hline$\sigma_{\max }(\mathrm{MPa})$ & 97.3 & 61.9 & 52.1 \\
$N_{\text {scan } 1}$ (cycles) & 0 & 0 & 0 \\
$N_{\text {scan } 2}$ (cycles) & 500 & 500 & 500 \\
$N_{\text {scan3 }}$ (cycles) & 1000 & 1000 & 1000 \\
$N_{\text {scan } 4}$ (cycles) & 1500 & 1500 & 1500 \\
$N_{\text {scan } 5}$ (cycles) & 2460 & 1510 & 2000 \\
$N_{\text {scan }}$ (cycles) & - & - & 2500 \\
$N_{\text {rupture }}$ (cycles) & 2468 & 1537 & 2527 \\
\hline
\end{tabular}

tensile tests results as on full scale normalized tensile specimens obtained by the same process.

The polyamide matrix is known to be sensitive to the conditioning [13,17-22]. The water uptake can lead to a larger ductility of the polymer. Therefore, ensuring the material RH stability before and during testing is important. Prior testing, the specimens were put in an environmental chamber at $70^{\circ} \mathrm{C}, \mathrm{RH}=62 \%$ of humidity until their water uptake stabilization. Then, they passed 15 days at $23^{\circ} \mathrm{C}$, $\mathrm{RH}=50 \%$ to led to the desired equilibrium humidity content of $50 \%$ of relative humidity (RH50 specimens). After conditioning, specimens are sealed in individual packets to prevent any change in RH and opened just before testing. Due to the short duration of each experiment, the water content was considered as constant between the beginning and the end of the tensile tests.

\subsection{Testing procedure}

The in situ X-ray microtomography fatigue tests consist in a succession of scans and loading blocks, until total failure of the specimen. Fatigue tests are performed under load control, at a loading ratio of 0.1 and a frequency of $3 \mathrm{~Hz}$. During each microtomographic scan, the specimen load is maintained at a small load (one third of the maximal load applied in fatigue). This load allows to evidence more easily damage mechanisms, thanks to a clear distinction between elements, for instance to distinguish two parts of a broken fiber in the bulk of the material. The scan time was of 3-5 min. This procedure helped to identify damage while the applied load was sufficiently small not to induce damage. For short lifetime ranges (around 2500 cycles), a scan is made after 500 cycles.

For the in situ observations combined with fatigue testing, 5 scans have been obtained for each specimen, as indicated in Table 1 .

\section{Results}

\subsection{Fractography}

After fatigue failure, specimen fracture surfaces have been observed by SEM. The entire fracture surface for short lifetime (2500 cycles) is presented in Fig. 3 for different orientations. The core layer clearly appears, vertically at the center of each specimen. At this scale, it can be noticed that when fibers are oriented perpendicularly to the loading direction (core layer of $0^{\circ}$ oriented specimen and shell layers of $90^{\circ}$ oriented specimen), the fracture surface is flatter than when fibers are parallel to the loading direction (shell layers of $0^{\circ}$ oriented specimen and core layer of $90^{\circ}$ oriented specimen). Due to the core-shell-skin structure, it should be noticed that the core and the shell parts of the specimen exhibit different roughness. In the case of $45^{\circ}$ oriented fibers (cf. 3(b)), the fracture surface presents an important roughness. The roughness is directly related to the respective orientation of the crack propagation direction and fiber orientation. The fracture surface roughness is high (resp. low) when the crack propagates

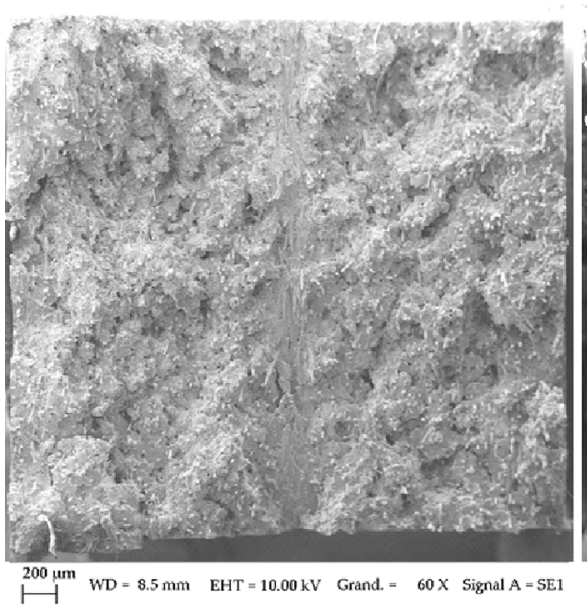

(a) $0^{\circ}$ oriented specimen

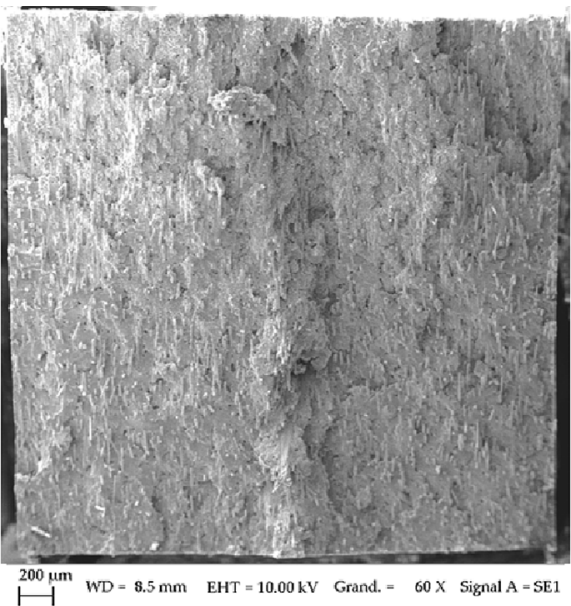

(b) $45^{\circ}$ oriented specimen

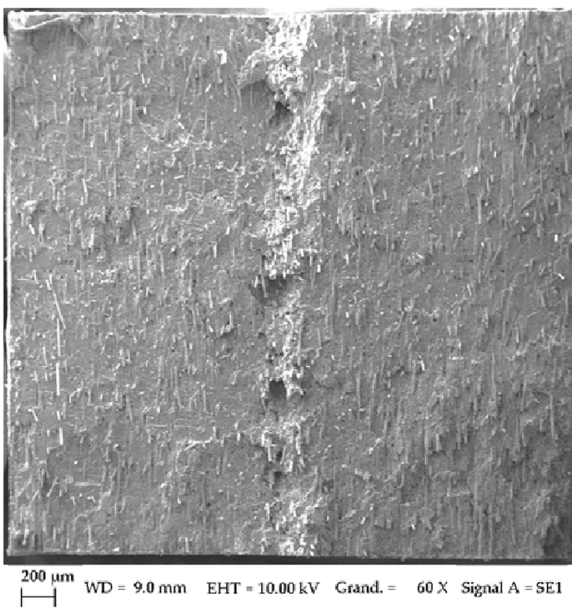

(c) $90^{\circ}$ oriented specimen

Fig. 3. Fracture surface observed by SEM - RH50 specimens - short lifetime range. 


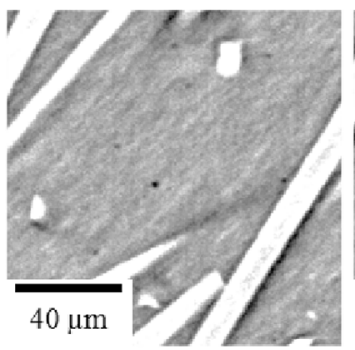

(a) $N / N_{R}=0.0 \%$

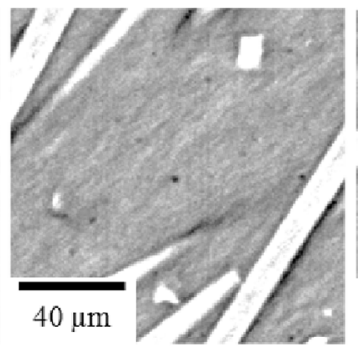

(b) $N / N_{R}=32.5 \%$

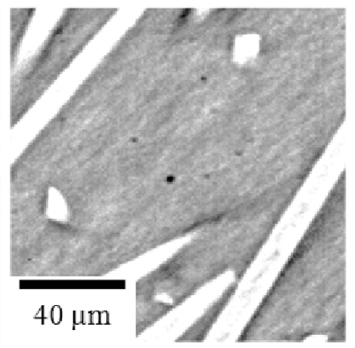

(c) $N / N_{R}=65.0 \%$

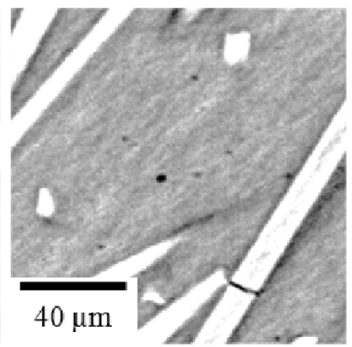

(d) $N / N_{R}=97.5 \%$

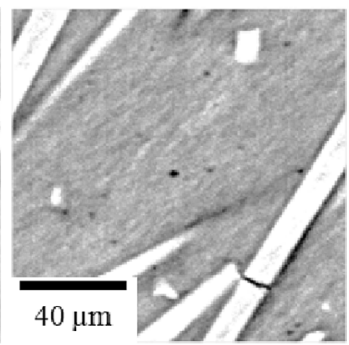

(e) $N / N_{R}=98.2 \%$

Fig. 4. Cavitation - RH50 $45^{\circ}$ specimen $N_{R}=1537$ cycles.
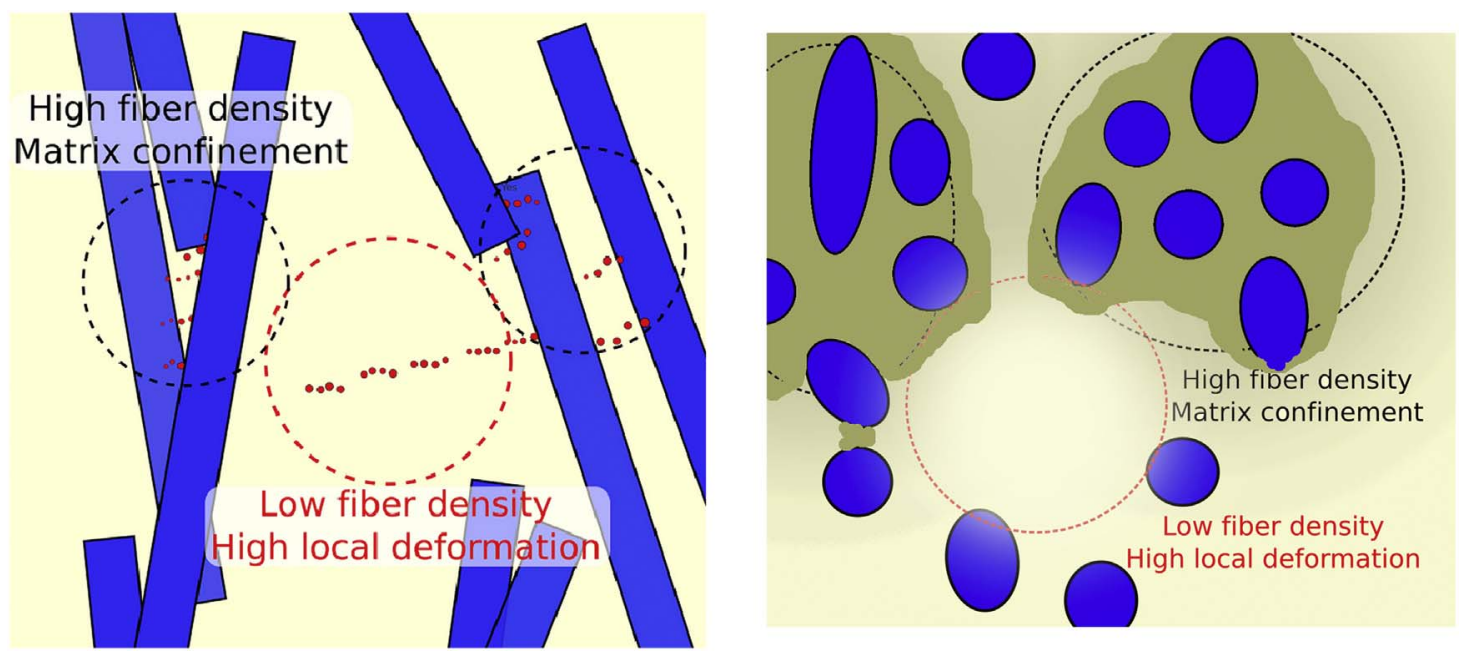

Fig. 5. High or low fiber density zones leading to damage initiation.

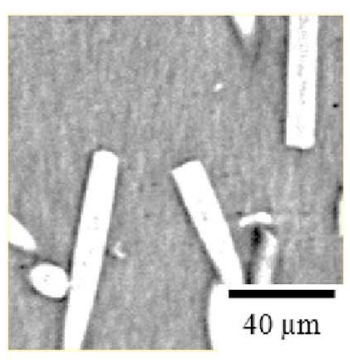

(a) $N / N_{R}=0.0 \%$

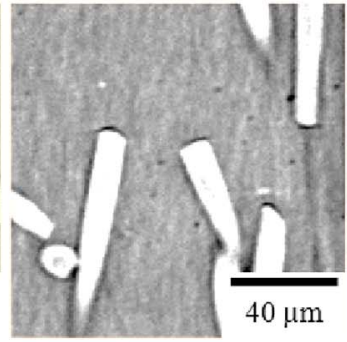

(b) $N / N_{R}=20.3 \%$

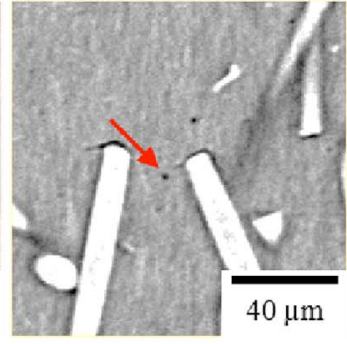

(c) $N / N_{R}=40.5 \%$

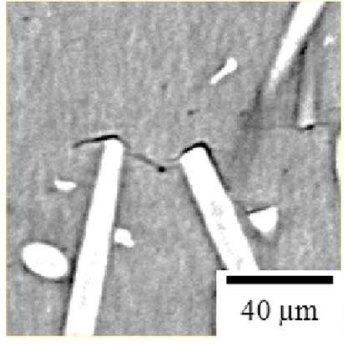

(d) $N / N_{R}=60.8 \%$ (e) $N / N_{R}=99.7 \%$

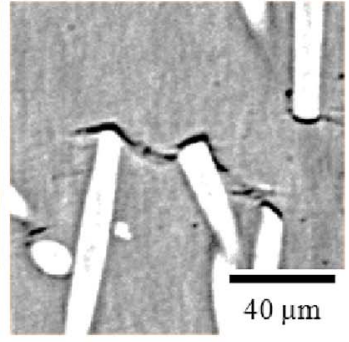

Fig. 6. Damage at fiber ends - RH50 $0^{\circ}$ specimen $N_{R}=2468$ cycles.

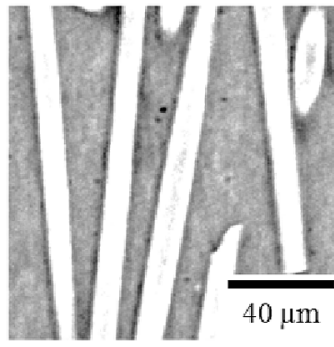

(a) $N / N_{R}=0.0 \%$

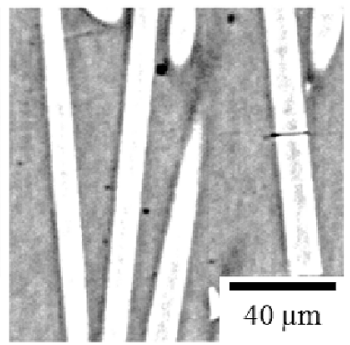

(b) $N / N_{R}=20.3 \%$

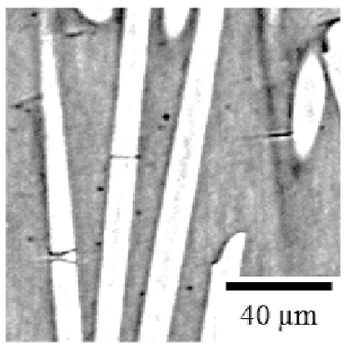

(c) $N / N_{R}=40.5 \%$
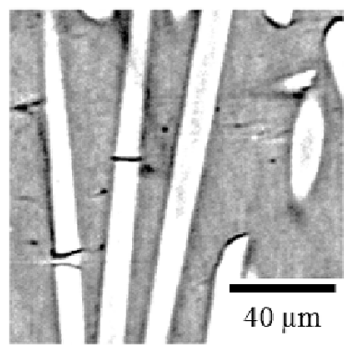

(d) $N / N_{R}=60.8 \%$

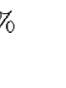




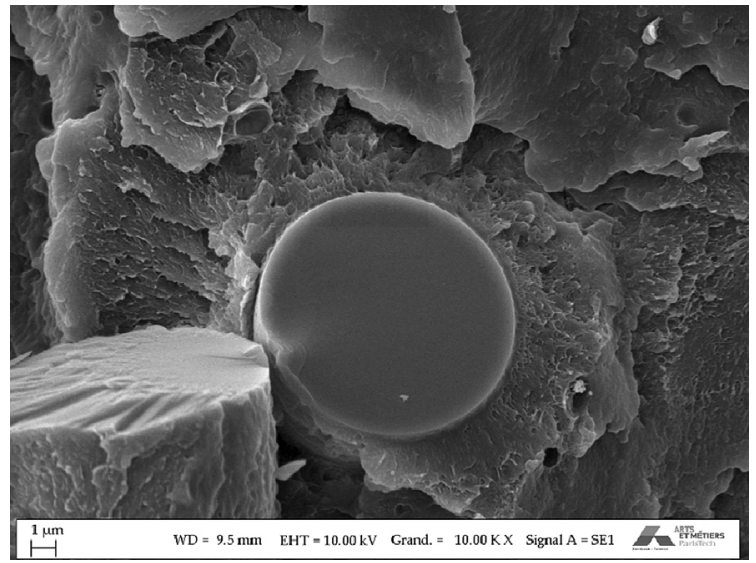

Fig. 8. SEM observation of fiber failure initiated by fretting-fatigue on the fracture surface - RH50 $45^{\circ}$ specimen.

perpendicularly to the fiber orientation (resp. parallel to the fiber orientation).

These fracture surfaces present mechanisms usually described in the literature $[5,6,23-25]$ such as fiber failure and fiber-matrix decohesion. Such post mortem analyses do not allow to explain which mechanisms lead to the final failure of the specimen neither their evolution during the fatigue lifetime. These two aspects can be evaluated with in situ Xray microtomographic observations, as presented in the following paragraphs.

\subsection{Elementary fatigue mechanisms description}

Six damage mechanisms have been observed in the bulk of the specimen: fiber failure, damage at fibre ends, debonding, cavitation, crazing and microcracks. A description of these mechanisms is proposed, focusing on their initiation, growth and interactions.

\subsubsection{Cavitation}

The cavitation mechanism relates to the creation of small spherical damage markers. Cavities may pre-exist in the polymer due to the injection process and due to heterogeneous density at the spherulite scale. Depending on their sizes, those cavities may $(d>1 \mu \mathrm{m})$ or may not $(d<1 \mu \mathrm{m})$ be detected on the tomographic image. When detected, they appear in the shape of spheres of 1-5 $\mu \mathrm{m}$ diameter.

These damage markers were found to appear from the first $10 \%$ on the fatigue life and to continuously initiate up to the final failure. The detected void size is quite stable from one scan to another, meaning that void do not grow significantly during the fatigue lifetime. However, it should be noticed that their number significantly increase with fatigue lifetime. This increase, driven by the applied cyclic loading, might be due to two main reasons: first voids may nucleate in defect free zones and second void may growth from pre-existing defects of a size lower than the minimum detectable one.

It should be noticed that this mechanism was not observed in such extent during monotonic tensile loading at the same load level [15] and such constitute a significant difference between quasi-static and fatigue damage mechanisms. From our observations, cavitation occurs either in fibre free zones or very close to the fiber-matrix interface, as shown in Fig. 4.

- In zones of low densities of fibers, the matrix is free to deform
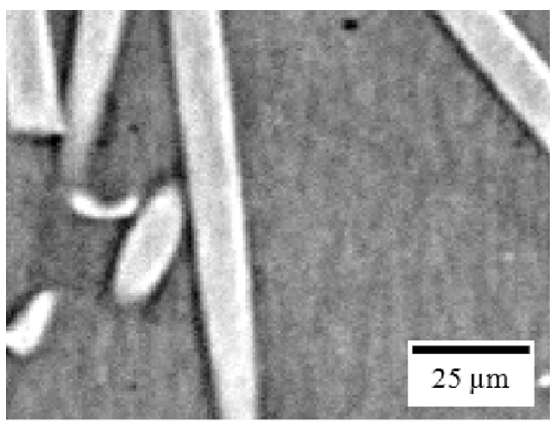

(a) Initial state $-N / N_{R}=0.0 \%$
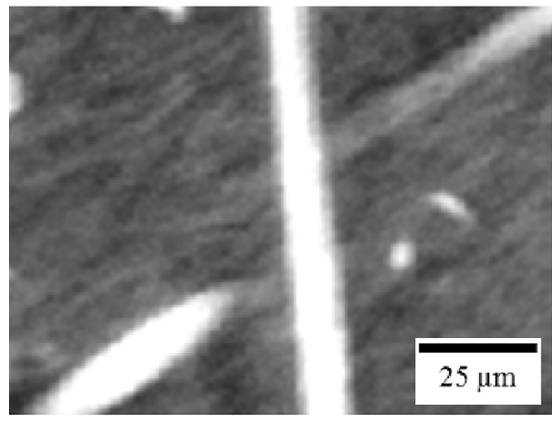

(d) Initial state $-\varepsilon / \varepsilon_{R}=0.0 \%$

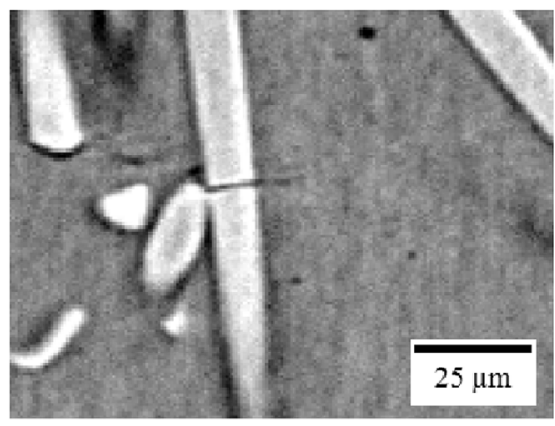

(b) fiber failure under cyclic loading $N / N_{R}=40.5 \%$
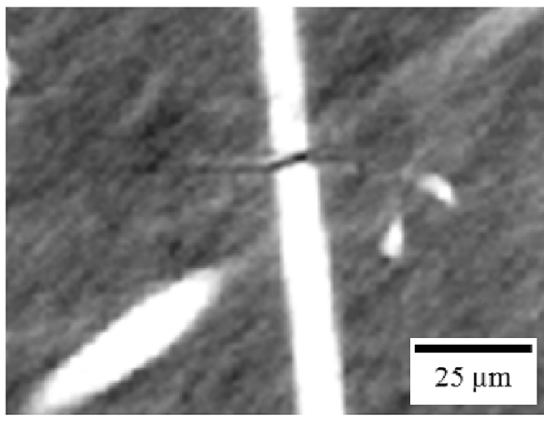

(e) fiber failure under monotonic loading

$-\varepsilon / \varepsilon_{R}=38.9 \%$

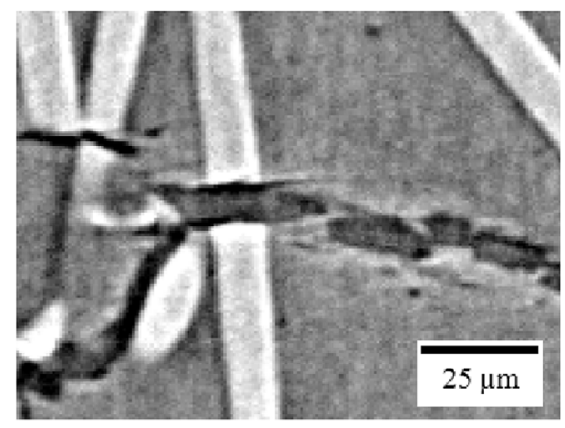

(c) Damage evolution under cyclic loading $-N / N_{R}=99.7 \%$

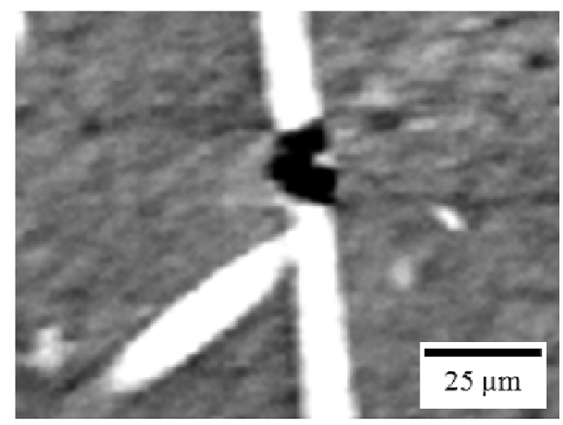

(f) Damage evolution under monotonic loading $-\varepsilon / \varepsilon_{R}=98.1 \%$

Fig. 9. Fiber failure evolution according to the loading. 


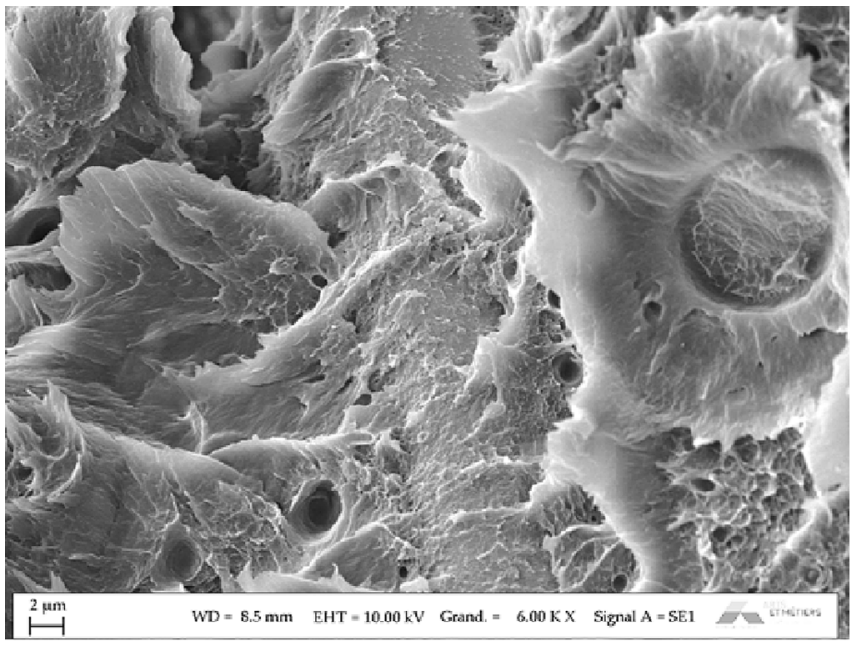

(a) Ductile zone

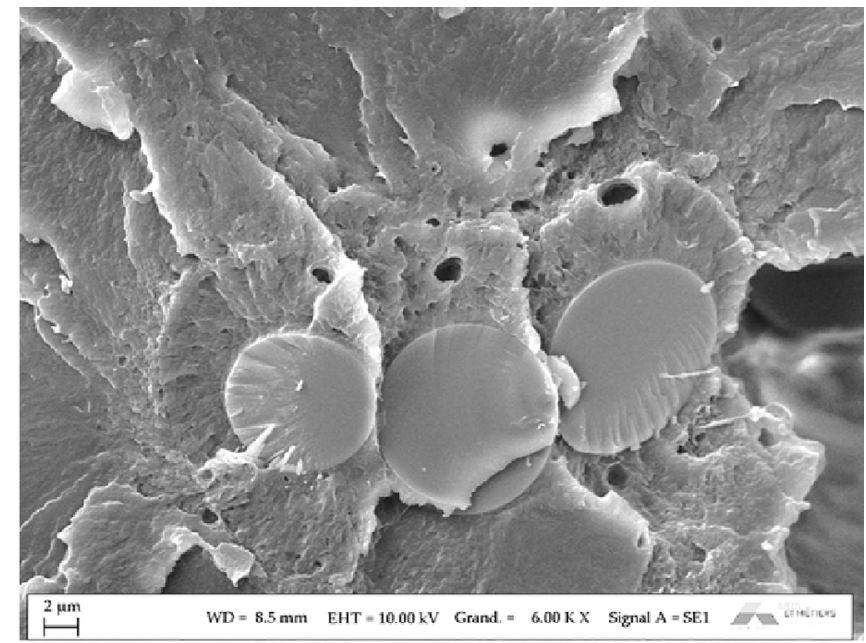

(b) Brittle zone

Fig. 10. SEM observations of fiber failures by fatigue on the fracture surface - RH50 $0^{\circ}$ specimen $N_{R}=2468$ cycles.

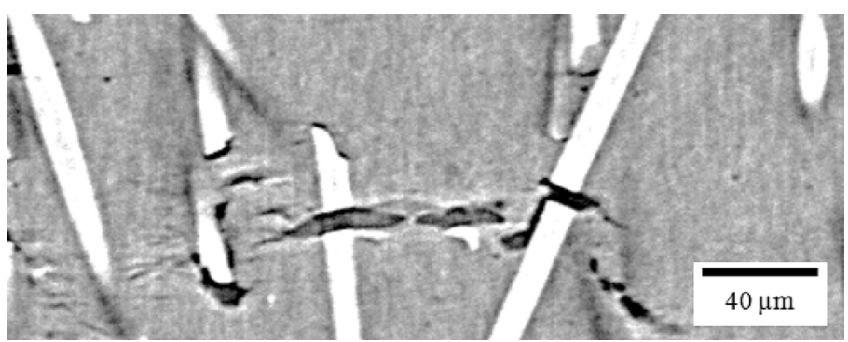

Fig. 11. Microcracks more developed around the fiber failure than at the fiber ends.

compared to the matrix that is confined and close to fibers. Due to the viscoelastic behavior of the material together with the applied loading ratio $(R=0.1)$ the mean strain evolves continuously as a function of the fatigue life. Lower fiber density zones, soft zones as compared to high fiber density zones, are more propitious to localized this mean strain component at the microscale. Work of Selles et al. [26] clearly indicates that under creep loading, cavitation is a privileged mode of damage development in the PA66. The mean strain evaluation under load control fatigue tests, that shows strong similarities with the long term evolution of the axial strain during creep tests together with the observed cavitation development correlate the results of Selles et al. [26].

- In the vicinity of fibers, the matrix is in a high local hydrostatic stress with a lower amorphous mobility. In semi-crystalline thermoplastics, these conditions are found to promote cavitation mechanism, as shown in the literature $[27,28]$.
Thus, under fatigue loading, the cavitation process can be activated in short fiber reinforced thermoplastics by two main parameters: the cyclic mean strain increase and/or high triaxiality level in the vicinity of fiber/matrix interface and confined matrix area (local high fiber density) at the microscale. A schematic view is proposed Fig. 5.

It should be noticed that those voids are also visible on fracture surfaces in both ductile and fragile fracture surface zones. Since the voids are visible on both, it is consistent with the fact that their population progressively evolves during fatigue loading and not only on localized zone corresponding to the final fracture.

\subsubsection{Damage at fiber ends}

The occurence of decohesion at fiber ends (also called fiber tips) has frequently been observed in our observations. This damage mechanism has also been observed for monotonic tensile testing [15,16] and is explained by the lack of bounding between fiber ends and matrix (due to the process) and the geometry of fibers, turning ends of fiber to stress concentrators. If these damage markers initiate at the first cycle in the same way as in quasi-static solicitation, they evolve very differently during the fatigue lifetime. Indeed, instead of growing in the matrix as for tensile loading by ductile damage growth [15], each damaged zone tends to initiate a microcrack in the matrix, transversely to the macroscopic tensile direction (as shown in Fig. 6). These damage zones can then be propitious to neighbouring microcracks propagation, depending on the sharpness of their geometry and the orientation of the edge. It should be noticed that the damage to microcrack transition is strongly dependent on the local configuration but starts at approximately $20 \%$ of the fatigue life. As observed in Fig. 6, damage progresses by coalescence of adjacent damaged zones. This coalescence is

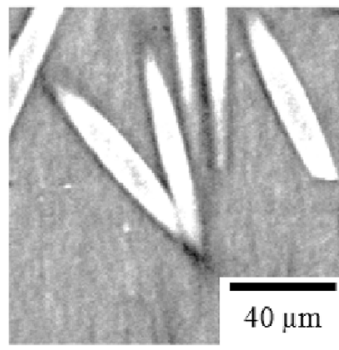

(a) $N / N_{R}=0.0 \%$

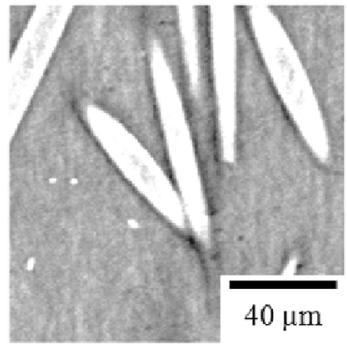

(b) $N / N_{R}=20.3 \%$

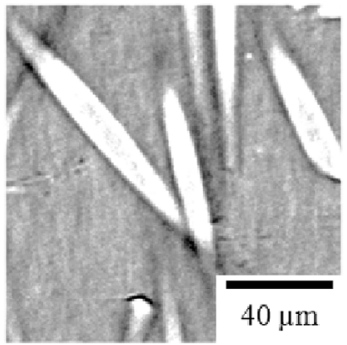

(c) $N / N_{R}=40.5 \%$

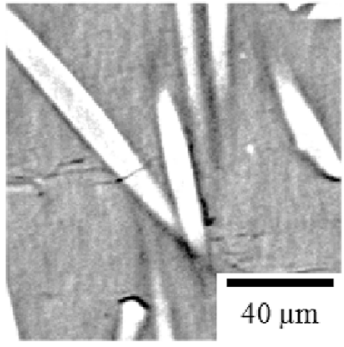

(d) $N / N_{R}=60.8 \%$

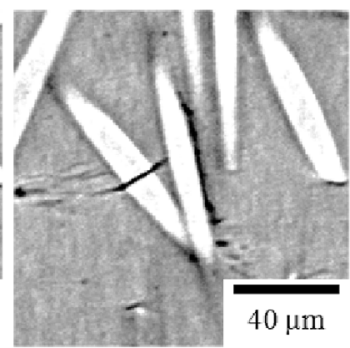

(e) $N / N_{R}=99.7 \%$

Fig. 12. Debonding - RH50 $0^{\circ}$ specimen $N_{R}=2468$ cycles. 


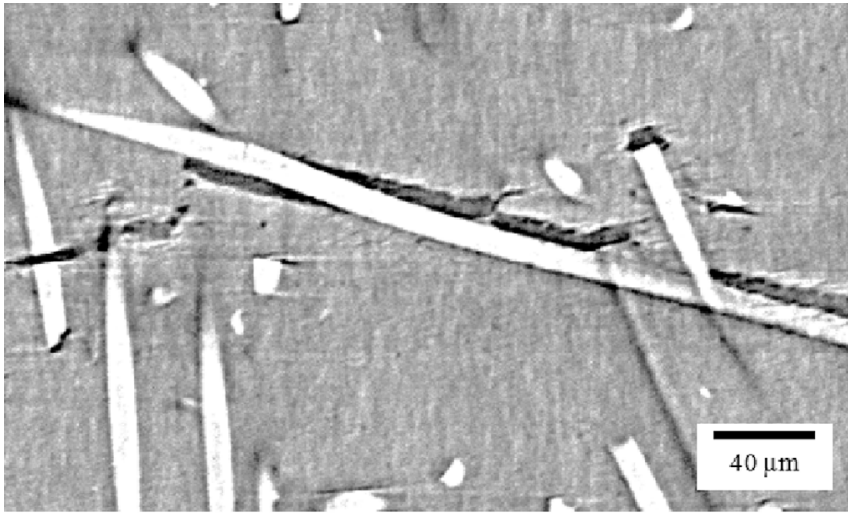

(a) Cohesive debonding $-N / N_{R}=99.7 \%$

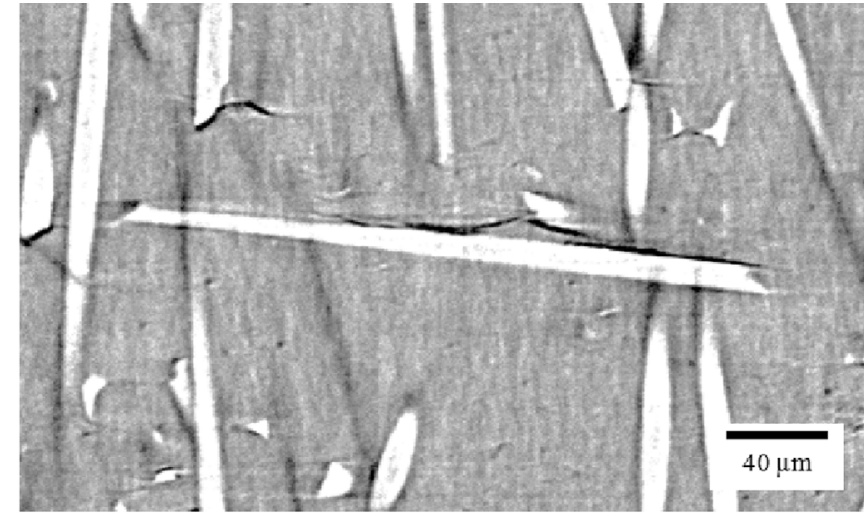

(b) Adhesive debonding $-N / N_{R}=99.7 \%$

Fig. 13. Different debonding - RH50 $0^{\circ}$ specimen.

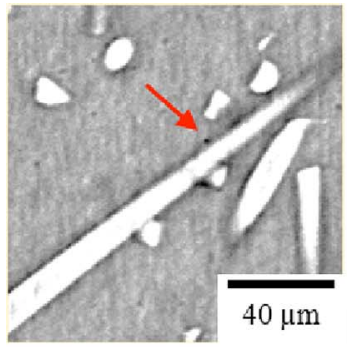

(a) $N / N_{R}=0.0 \%$

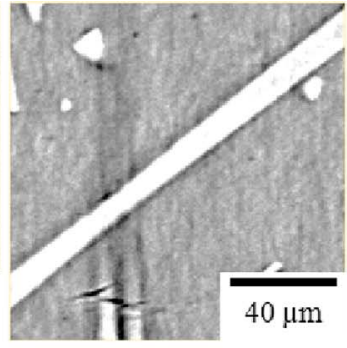

(b) $N / N_{R}=20.3 \%$

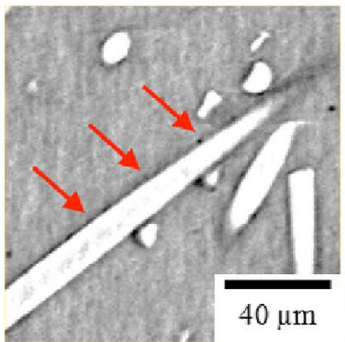

(c) $N / N_{R}=40.5 \%$

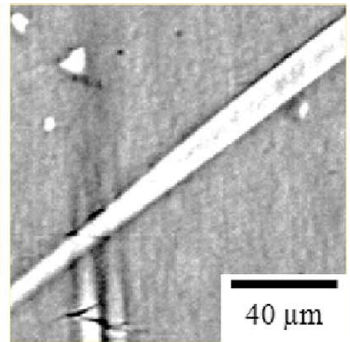

(d) $N / N_{R}=60.8 \%$

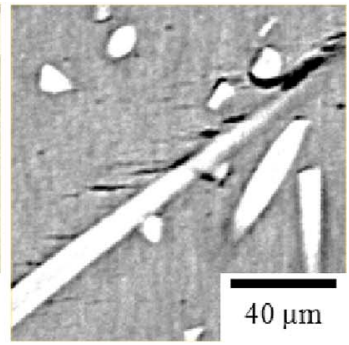

(e) $N / N_{R}=99.7 \%$

Fig. 14. Crazing - RH50 $0^{\circ}$ specimen $N_{R}=2468$ cycles, cavitation evidenced by arrows

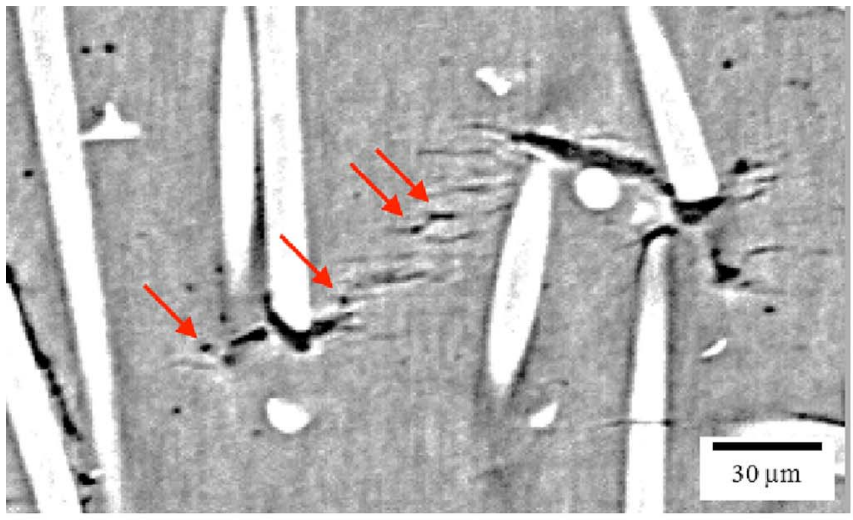

(a) In the matrix, between two damage zones - $N / N_{R}=99.7 \%$

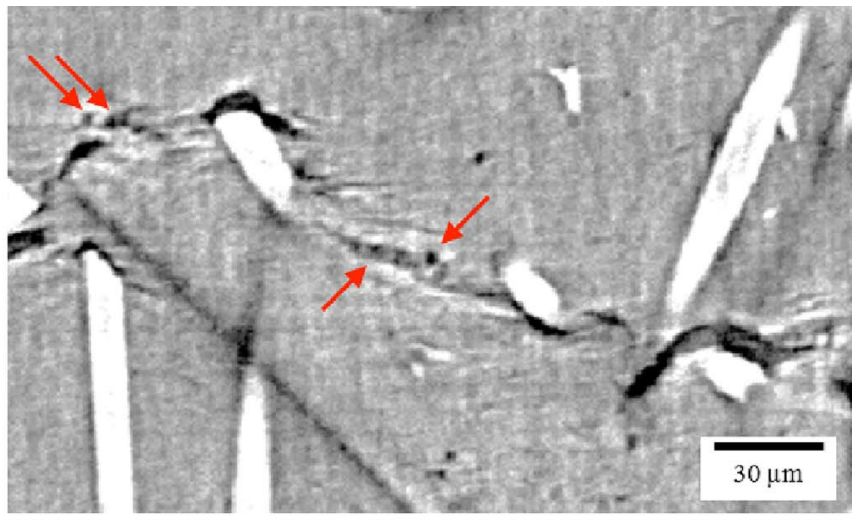

(b) From cavitation to crazing mechanism $-N / N_{R}=99.7 \%$

Fig. 15. Crazing - RH50 $0^{\circ}$ specimen, cavitation evidenced by arrows.

triggered by cavitation that initiates a microcrack in between two fiber ends (see Fig. 6(c)).

\subsubsection{Fiber failure}

Fiber failure was found to develop all along the fatigue life of the specimens and to a large extent for all fiber orientations. A typical sequence is given Fig. 7. Since fiber failure develops all along the fatigue life, it is reasonable to consider that fibers fail by fatigue and not by a quasi-static failure process (ie fibers do not fail at the very first cycle). Even though fibers are relatively short $(150-350 \mu m)$, their fragmentation in multiple parts was clearly observed.

Failure of individual fibre leads to local stress redistribution and successively foster the failure of neighbouring fibers and of the surrounding matrix. It is worth noting that when a fiber breaks, contrary to observations made for monotonic testing, the damage does not grow spherically but grows in the form of a microcrack transversely to the macroscopic loading as illustrated in Fig. 9, or by debonding and coalescence as in Fig. 7(e). These microcracks can also be found on the fracture surface as illustrated by SEM fractography given Fig. 10. Microcracks generated by the fiber failure appear as a disk around fibers, whether it is in ductile zone (see Fig. 10(a)) or in brittle zone (see Fig. 10(b)). These microcracks are due to high stress and strain concentration in the fiber failure zone. The higher criticity of fiber failure compared to fiber ends damage is illustrated in Fig. 11, where the microcracks are developing at the level of the fiber failure instead of fiber ends. 


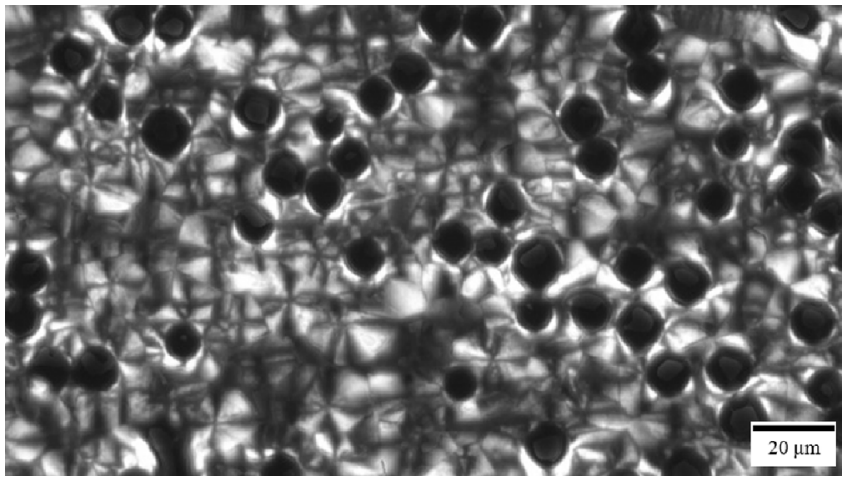

Fig. 16. RH50 $0^{\circ}$ specimen observed by optical microscopy in cross polarization.

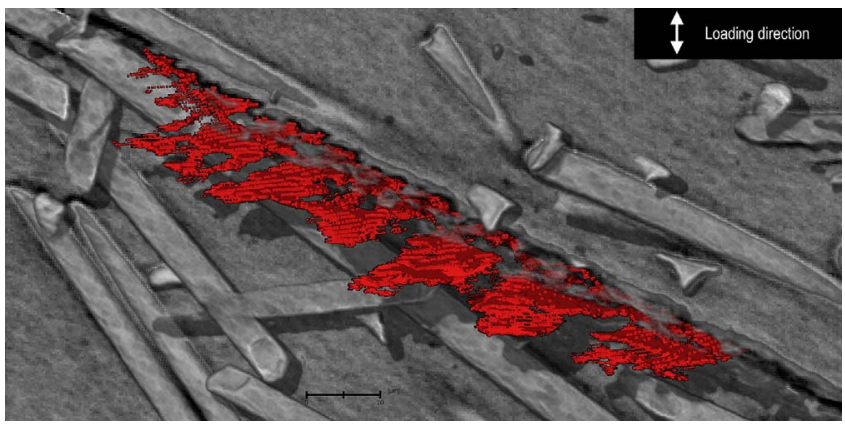

Fig. 17. Crazing segmented in a RH50 $45^{\circ}$ specimen.

An important aspect of fiber failure is its link with the crossing of adjacent fibers, called "fiber crossing" in the following. Fiber crossing has systematically been observed around broken fibers zones suggesting that local disorientation of close fibers represent a critical microstructural configuration. Two main reasons can explain the fact that fiber crossing promotes fiber failure:

- the presence of fibers with strong disorientation induces local overstress that triggers the failure of the fiber (this local over-stress is confirmed by numerical computations but not shown here). In that case fiber failure is due to cyclic high local stresses that induce fatigue failure of the fiber,

- it was often observed that the distance between crossing fibers is in the order of magnitude of the resolution of the tomographic image. Thus it is very probable that contact occurs between fibers, creating a local fretting-fatigue situation that could trigger the failure process. The existence of such a fretting like fatigue damage mechanism at the micro scale is confirmed by SEM observations (see Fig. 8) that clearly evidence damage in the contact zone in between two fibers.

Thus, the fiber failure mechanism plays a key role in the initiation microcracks during fatigue loading.

\subsubsection{Debonding}

Debonding occurs at the fiber-matrix interface, as illustrated in Fig. 12. It mainly happens along fibers oriented transversely to the macroscopic loading. This mechanism was observed to initiate from damage at fiber ends but, mostly by damage localization along the fiber at the fiber-matrix interface, promoted by a confinement effect between neighbouring fibers. Debonding mostly appears at an advanced stage of the fatigue lifetime (approximately $90 \%$ ) and contributes significantly to the meso-crack propagation process. As usually considered, debonding may appear as an adhesive or cohesive process (illustrated in Fig. 13). The nature of debonding appear to be linked to the orientation of the fibers, on the neighbouring fibers (confinement effect) and on the quality of the interface (e.g. regularity of the sizing). In the case of adhesive failure, debonding was clearly initiated by the development of multiple cavitation at the fiber matrix interface. Damage then develops in the form of penny-shape voids (micro-crack similar to the crazes described in the next section) of a typical size of five to ten micron that quickly connect to form an interfacial debonding. It should be noticed that debonding was found to be triggered by cavitation along the fibermatrix interface. In our case, debonding was mostly a cohesive failure process, promoted by proper chemical fiber-matrix treatments.

\subsubsection{Crazing - fibrillation}

Crazes are damaged zones of the matrix, where fibrils are still present between the two sides of the damage marker and of a typical size of $10-30 \mu \mathrm{m}$ and appear in the last stage of the fatigue life. Once again cavitation plays a major role in this process. Indeed crazes were found to initiated by cavitation of the matrix and observed close to the fiber-matrix interface (see Fig. 14) or between pre-damaged zones of the matrix (see Fig. 15(a)), often in shear-band like localized zones. All the crazes are oriented transversely to the macroscopic loading, whatever they are close to a fiber-matrix interface or in the matrix. In the case of near fiber-matrix interface crazes there are strong similarities with the decohesion process. In both cases cavitation initiates the process and penny-shape voids can be observed in the first stage. The only difference is the fiber orientation with respect to the loading direction. In the case of fibers near perpendicular to the loading direction, voids grow on the same plane and connect to form a cohesive debonding. For lower angles $\left(80^{\circ}-30^{\circ}\right)$ voids do not grow on the same plane so that a full population of voids might be observed as observed Fig. 16. The growth of each damage marker seems limited in size, with a characteristic length between a few microns and $20 \mu \mathrm{m}$. Remarkably, this length range is equivalent to spherulites diameter obtained by optical microscopy (see Fig. 16). This correlation is further confirmed by the three-dimensional segmentation of craze inside the thermoplastic matrix given Fig. 17 (near a fiber matrix interface). These structures are flat, penny shape like volumes of about $20 \mu \mathrm{m}$ in diameter. These observations strongly suggest that each craze correspond to the damage of one spherulite and is initiated by cavitation in the core of the

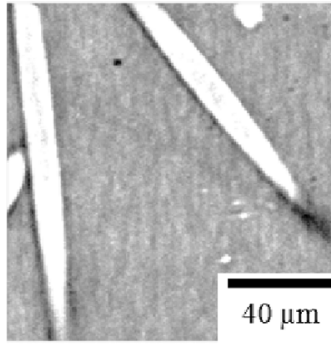

(a) $N / N_{R}=0.0 \%$

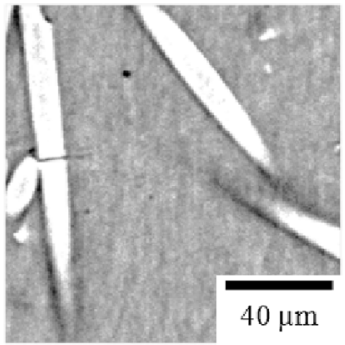

(b) $N / N_{R}=20.3 \%$

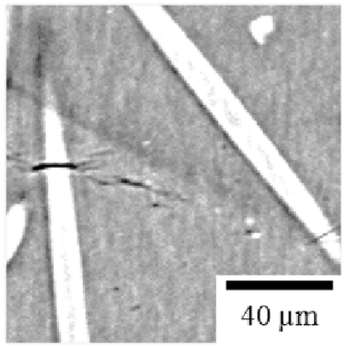

(c) $N / N_{R}=40.5 \%$

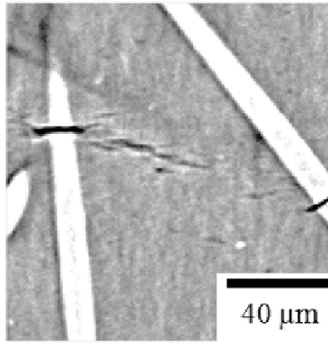

(d) $N / N_{R}=60.8 \%$

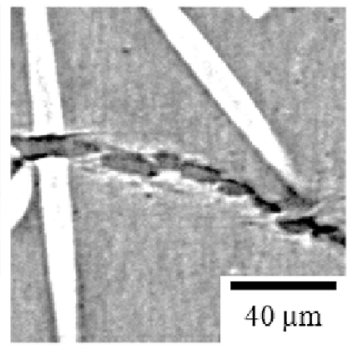

(e) $N / N_{R}=99.7 \%$

Fig. 18. Microcracks - RH50 $0^{\circ}$ specimen $N_{R}=2468$ cycles. 


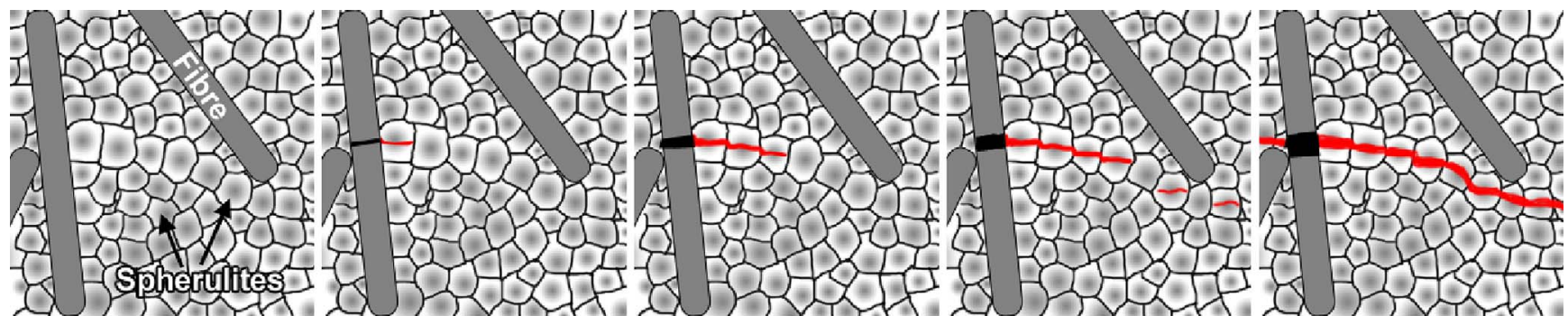
(a) $N / N_{R}=0.0 \%$
(b) $N / N_{R}=20.3 \%$
(c) $N / N_{R}=40.5 \%$
(d) $N / N_{R}=60.8 \%$
(e) $N / N_{R}=99.7 \%$

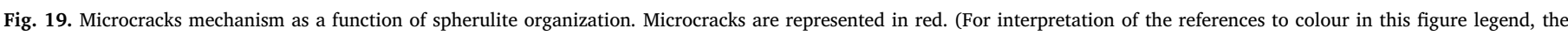
reader is referred to the Web version of this article.)

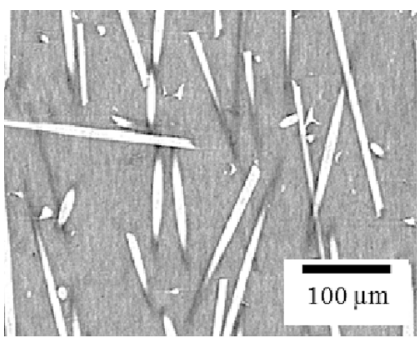

(a) Initial state

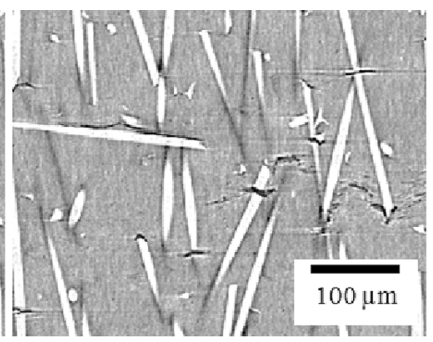

(b) $N / N_{R}=99.7 \%$

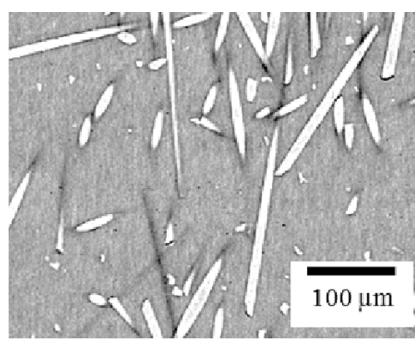

(c) Initial state

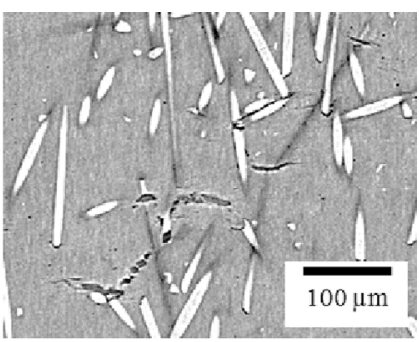

(d) $N / N_{R}=99.7 \%$

Fig. 20. Microcracks localization - RH50 $0^{\circ}$ specimen.

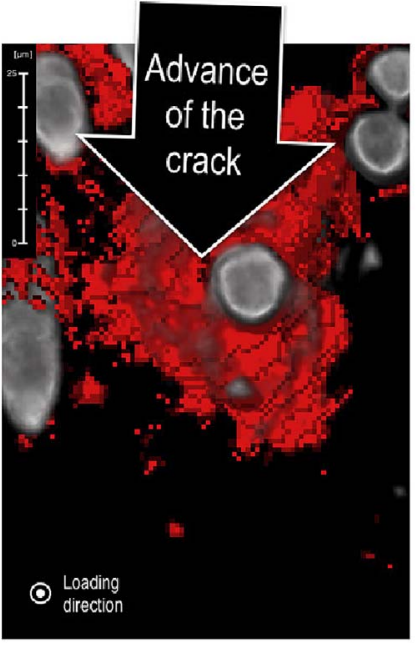

(a) After 2460 loading cycles

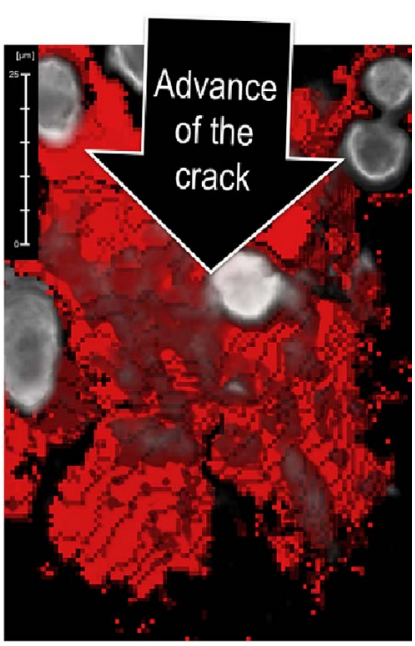

(b) After 2462 loading cycles
Fig. 21. Advance of the crack tip, segmented in a RH50 $0^{\circ}$ specimen and viewed in the plane orthogonal to the loading direction, revealing the relationship between microcrack geometry and spherulitic structure.

spherulite. This observation is of particular importance since it directly links the development of fatigue damage with the spherulite size.

\subsubsection{Microcracks}

Microcracks have only been observed in advanced steps of the fatigue lifetime, as illustrated in Figs. 18 and 19. Microcracks larger than a few hundred microns result from the growth and coalescence of damage markers in highly damaged zones. The propagation rate and the crack path are highly dependent on the local microstructure, and especially on the disposition of damage markers and fiber orientation. If microcracks rely on the junction of elementary damage markers, their local orientation is not systematically transverse to the macroscopic loading, each individual fiber representing a microstructural barrier to overcome. In the case of $0^{\circ}$ specimens, the propagation process is mostly driven by localization of damage in the form of $45^{\circ}$ bands in between pre-existing damage zones, as observed in Fig. 20. For $90^{\circ}$ specimens, the damage coalescence is promoted by the favourable orientation of the fiber-matrix interface that provides an easy crack propagation path. It has to be noticed that, at the specimen scale, $0^{\circ}$ specimens provide a more important density of microcracks than $90^{\circ}$ specimens where the transition from microcracks to a critical mesocracks appears more sudden. $0^{\circ}$ specimens appear far more damage tolerant than $90^{\circ}$ specimens.

As for damage initiation, microcracks seem to progress by steps with a size that corresponds to the spherulite size, as illustrated in Fig. 19. This observation is confirmed by the three-dimensional segmentation of microcracks (Fig. 21) as they form in the thermoplastic matrix. Microcracks are also penny shape like volumes, with a diameter close to the spherulite size.

\subsubsection{From microcracks to mesocracks}

During fatigue tests, the maximum strain per cycle was monitored. As soon as a deviation of this parameter was observed, the test was stopped in order to check if a particular event happened in the specimen. In each case, a thin line was visible to the naked eye (mesocrack) in the gage length o the specimen. In order to observe this region at the microstructural level, the subsequent microtomography scans were recentered on it.

The mesocrack appears in a region of the specimen where microcracks were well developed and where numerous elementary damage markers were present, as shown on a slice of a microtomographic picture of a fatigued $0^{\circ}$ specimen on Fig. 22.

The path of the mesocrack from a specimen to another are significantly influenced by the local fiber orientation.

\section{- $0^{\circ}$ specimen}

In $0^{\circ}$ oriented specimen, the mesocrack appeared centered on the core zone layer, as illustrated in Fig. 23. In the core, where most of 


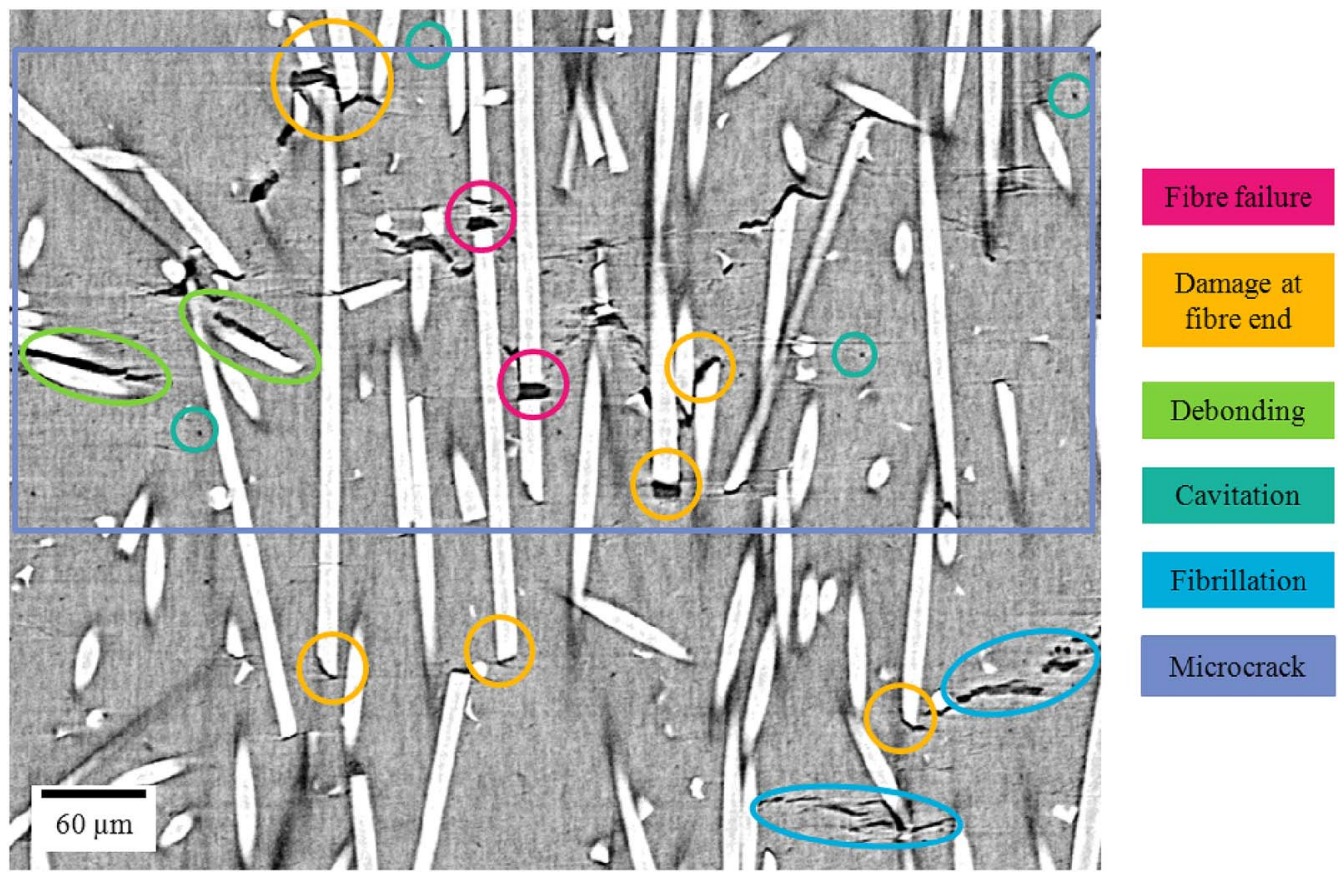

Fig. 22. X-ray microtomography observation in the bulk of fatigued $\left(N / N_{R}=98.2 \%\right)$ RH50 $0^{\circ}$ specimen.

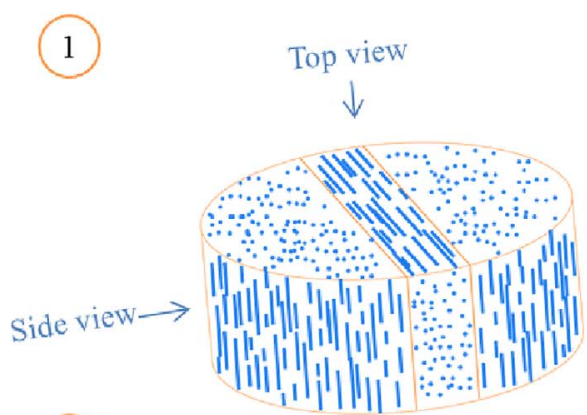

(2)

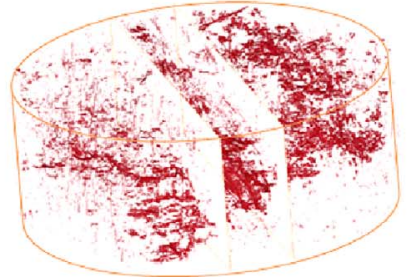

(a) 1) fiber orientation in the observed volume. 2) Damage in the observed volume

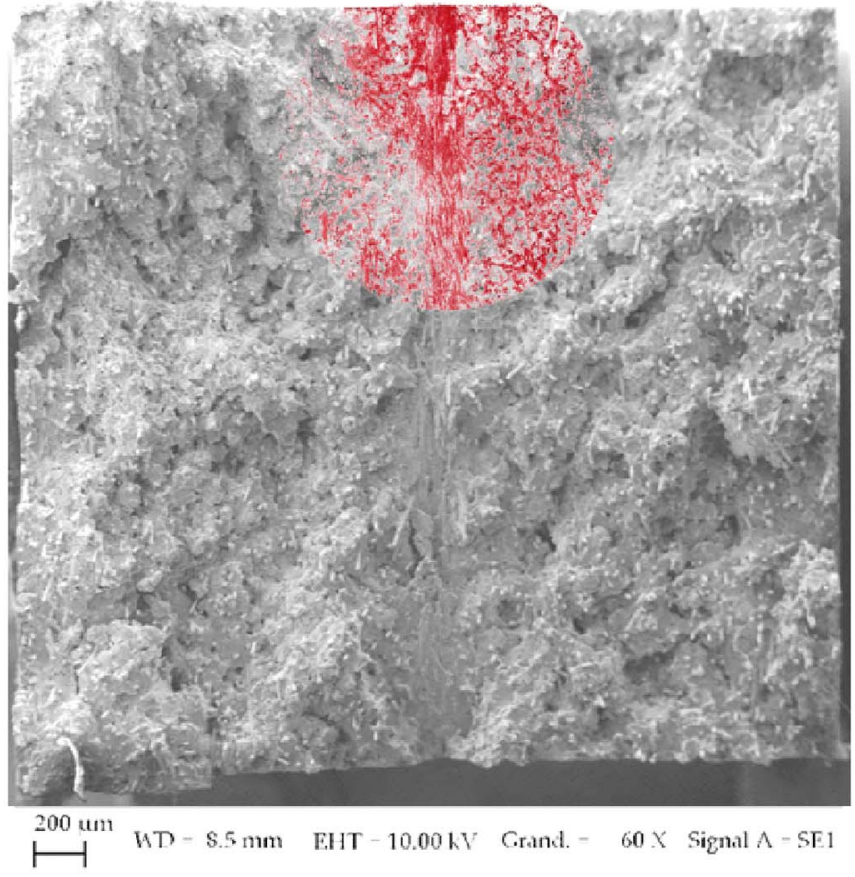

(b) Top view of damage superposed on broken surface of the specimen

Fig. 23. Microcracks localization - RH50 $0^{\circ}$ specimen.

fibers are oriented at $90^{\circ}$, the mesocrack consists of fiber-matrix debonding and fiber failure of fibers transverse to the macroscopic loading (see Fig. 24(a)). In the matrix, microcracks are also clearly transverse to the macroscopic loading. These elements lead to a relatively straight path of the mesocrack in the core of $0^{\circ}$ oriented specimen (see Fig. 24(b)).

On the contrary, the path is really tortuous in the shell, where fibers are oriented at $0^{\circ}$, as presented in Fig. 24(c) and (d). The tortuosity results from the presence of fibers perpendicular to the mesoscopic direction that represent microstructural barriers to overcome and induce crack deviation by shear localization at the micro scale as discussed previously. The mesocrack propagation process is mostly based on damage initiation and coalescence at fiber ends of fibers parallel to the macroscopic loading and of shear at the interface of fibers between highly deformed local zones leading to their debonding and contributing to the connection of microcracks. At the macroscopic scale the 


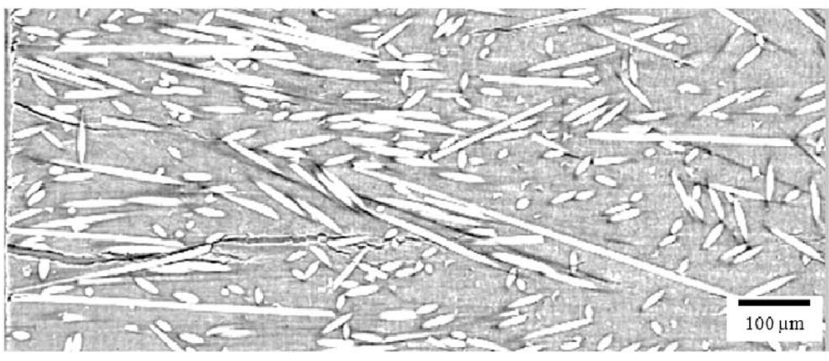

(a) Slice of the core (fibers oriented at $90^{\circ}$ )

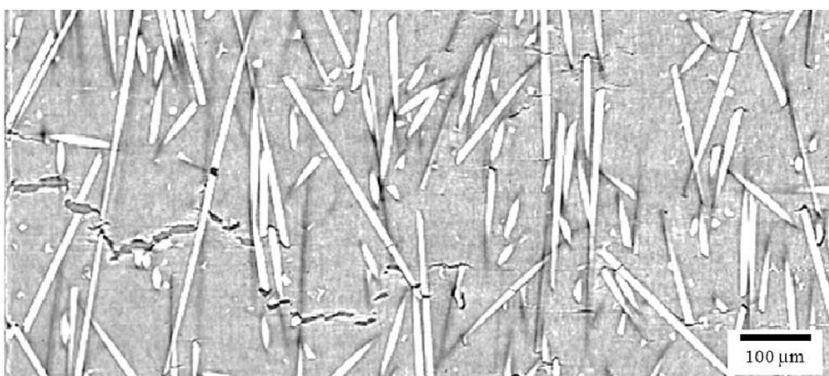

(c) Slice of the shell (fibers oriented at $0^{\circ}$ )

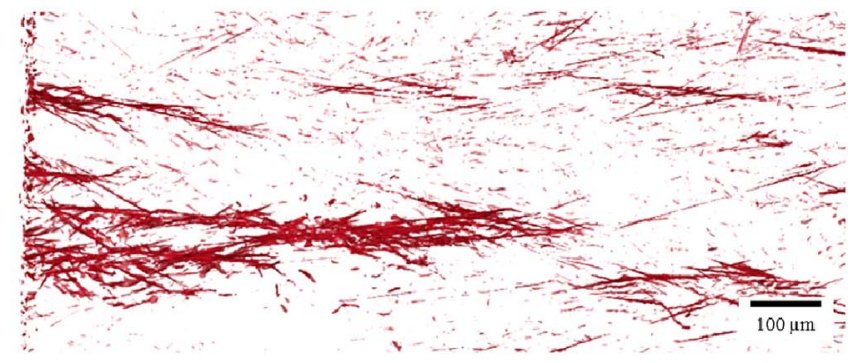

(b) Damage in the core (fibers oriented at $90^{\circ}$ )

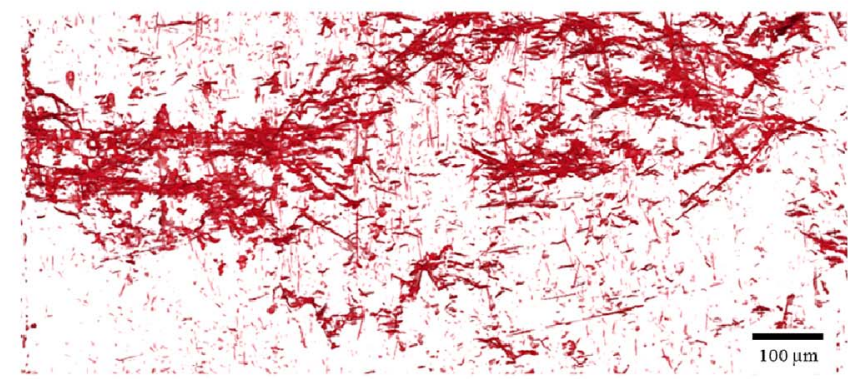

(d) Damage in the shell (fibers oriented at $0^{\circ}$ )

Fig. 24. Side view of mesocracks - RH50 $0^{\circ}$ specimen.

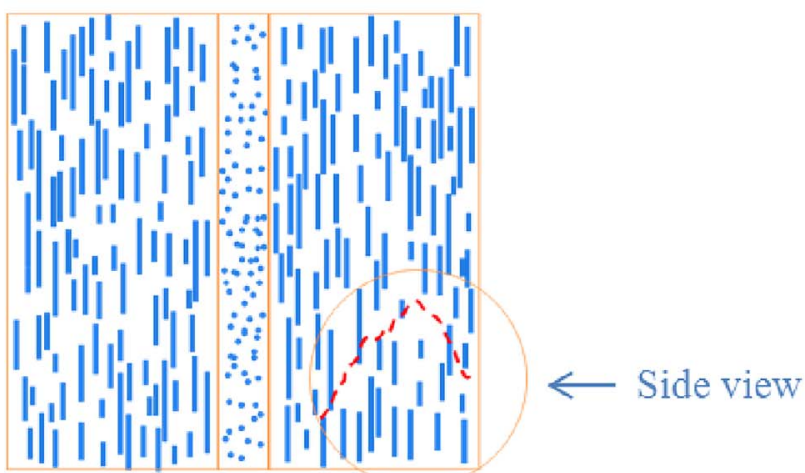

(a) fiber orientation in the observed volume

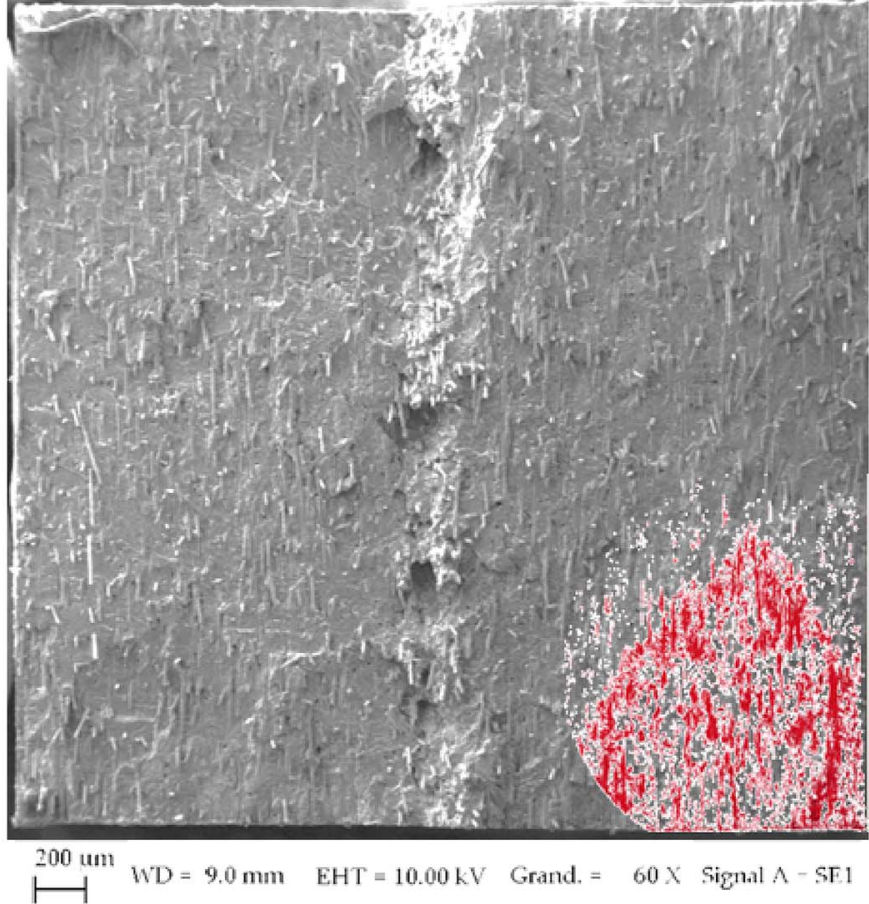

(b) Top view of damage superposed on broken surface of the specimen

Fig. 25. Microcracks localization - RH50 $90^{\circ}$ specimen.

crack propagates perpendicularly to the loading direction but is found to be very tortuous at the mesoscopic scale. The tortuosity results from the presence of fibers perpendicular to the mesoscopic direction that represent microstructural barriers to overcome and induce crack deviation by shear localization at the micro scale. The high density of shear localization and the resulting tortuosity of the meso crack suggests a highly dissipative process compared to $90^{\circ}$ specimens.

\section{- $90^{\circ}$ specimen}

In $90^{\circ}$ oriented specimen, the mesocrack appeared in a corner of the specimen, as illustrated in Fig. 25, where fibers are oriented 


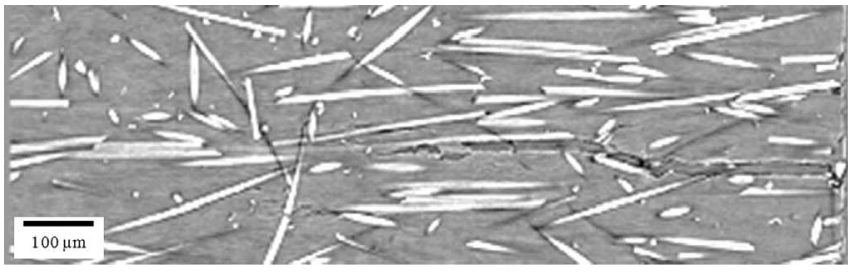

(a) Slice (fibers oriented at $90^{\circ}$ )

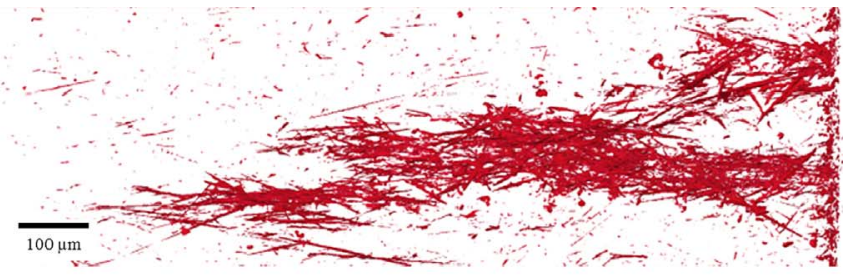

(b) Damage (fibers oriented at $90^{\circ}$ )

Fig. 26. Side view of mesocracks - RH50 $90^{\circ}$ specimen.

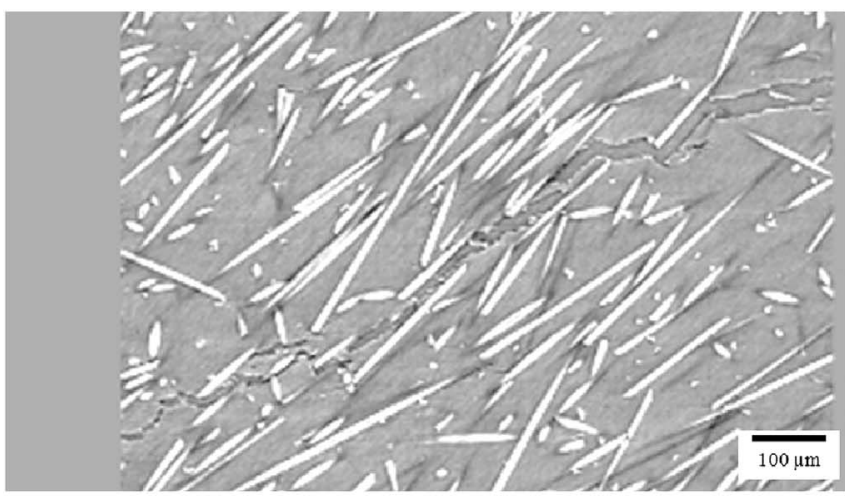

(a) Slice (fibers oriented at $45^{\circ}$ )

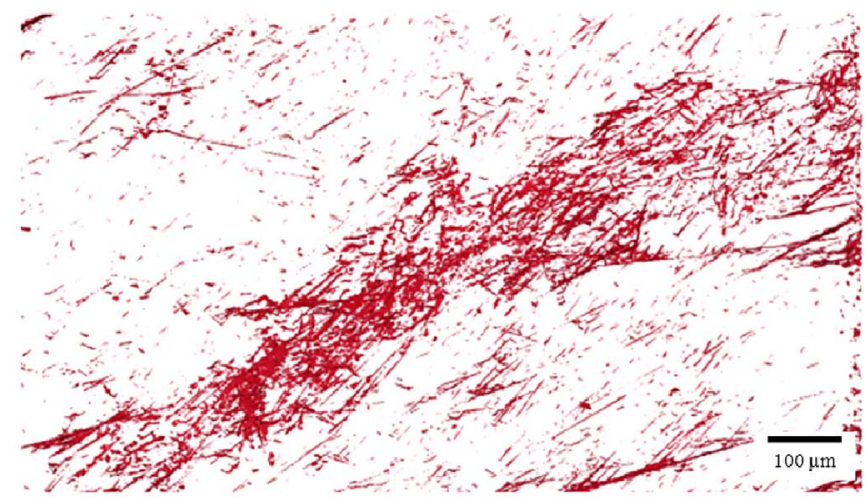

(b) Damage (fibers oriented at $45^{\circ}$ )

Fig. 27. Side view of mesocracks - RH50 $45^{\circ}$ specimen.

transversely to the macroscopic loading direction. The mesocrack path is similar to the part of the mesocrack in the core of the $0^{\circ}$ specimen: it is mainly based on debonding at the interface and forms a relatively straight path (see Fig. 26). This propagation is a far less dissipative process than the one acting on $0^{\circ}$ specimens, since the density of damage markers, shear localization zones and the developed surface of the crack is of several order of magnitude lower than in the $0^{\circ}$ specimens.

\section{- $45^{\circ}$ specimen}

In the case of $45^{\circ}$ specimen, fibers of both shell and core form an angle of $45^{\circ}$ with the macroscopic loading direction. This orientation leads to differences of crack propagation. The mesocrack is mainly based on damage at the interface: debonding and damage at fiber ends, as presented in Fig. 27. From the interface of one fiber to another, the propagation through the matrix is mainly transverse to the macroscopic loading.

Globally, the mesocrack path is an in between configuration form the one of $0^{\circ}$ and $90^{\circ}$ specimens, driven by both fiber-matrix debonding and matrix damage coalescence. Thus, the propagation process in a $45^{\circ}$ specimen is slightly more dissipative than in the case of $90^{\circ}$ specimen.

\section{Concluding remarks}

This study presents the first results by in situ microtomographic fatigue tests on reinforced thermoplastics, with low voxel edge size $0.65 \mu \mathrm{m}$. The elementary mechanisms that occur during the fatigue lifetime of the short glass fiber reinforced polyamide 6,6 have been evidenced: fiber failure, debonding or damage at fiber ends and matrix damages (cavitation, fibrillation and cracks formation). From observations it is clearly evidenced that cavitation plays a major role in the fatigue damage process as it triggers all microscale elementary damage mechanisms observed. The cavitation process is promoted by local fiber configuration: low fiber density leads to cavitation through high deformation of the matrix whereas high fiber density leads to cavitation through matrix confinement between close fibers. The presented observations will be compared to full field microstructure computation in a fore-coming paper. It can then be conclude that controlling the cavitation behavior of the polymer may lead to significantly enhanced fatigue properties of the composite material.

It was also shown that a characteristic length appears in the fatigue damage development. The crazing development during fatigue tests show a characteristic size of $10-20 \mu \mathrm{m}$ and a specific orientation, which can respectively be linked to the spherulite size and spherulitic failure in the equatorial region, as observed in another polyamide material [26]. This internal length is in the order of magnitude of the spehrulite size, suggesting a strong impact of the spherulite size on the fatigue damage development.

A comparison between fatigue and monotonic damage mechanisms shows some similarities (dependency on zones of fiber confinement) but some major differences, particularly concerning matrix damage and damage evolution. Indeed, fatigue testing induced important cavitation and fibrillation development compared to monotonic loadings. It also has to be noticed that damaged zones did not grow as during tensile tests with large local deformation, but propagates in the form of mesocrack by damage coalescence and micro-shear.

Finally the damage evolution during fatigue testing was found to be strongly dependant on local fiber orientation. Propagation is an oriented phenomenon and, according to the local fiber orientation, can be limited (perpendicular orientation of fibers) or favoured (fibers parallel to the microcrack). The propagation process in $0^{\circ}$ is a far much dissipative process than the one acting on $90^{\circ}$ and $45^{\circ}$ specimens since, in that case, fiber orientation promotes damage development in the full gage length of the specimen and meso-crack deviation and branching.

\section{Acknowledgement}

The authors gratefully acknowledge Solvay Engineering Plastics for supporting this work and for providing specimens. This work was 
performed in the framework of the DURAFIP project (FUI project supported by Oseo). The tomography experiments performed at SOLEIL Synchrotron were financially supported by the synchrotron proposal $n^{\circ} 20150398$

\section{References}

[1] Zhou Y, Mallick PK. Fatigue performance of an injection-molded short E-glass fiberreinforced polyamide 6,6. I. Effects of orientation, holes, and weld line. Polym Compos 2006;27:230-7.

[2] Bernasconi A, Davoli P, Basile A, Filippi A. Effect of fibre orientation on the fatigue behaviour of a short glass fibre reinforced polyamide-6. Int J Fatig 2007;29:199-208.

[3] Bernasconi A, Cosmi F, Dreossi D. Local anisotropy analysis of injection moulded fibre reinforced polymer composites. Compos Sci Technol 2008;68. 2754-2581.

[4] Lang RW, Manson JA, Hertzberg RW. Mechanisms of fatigue fracture in short glass fibre-reinforced polymers. J Mater Sci November 1987;22(11):4015-30.

[5] Horst JJ, Spoormaker JL. Mechanisms of fatigue in short glass fiber reinforced polyamide 6. Polym Eng Sci 1996;36(22):2718-26.

[6] Horst JJ, Spoormaker JL. Fatigue fracture mechanisms and fractography of shortglassfibre-reinforced polyamide 6. J Mater Sci 1997;32(14):3641-51.

[8] Belmonte E, De Monte M, Hoffmann C-J, Quaresimin Short M. Fiber reinforced plastics (SFRPs), fatigue, electron microscopy, injection molding, damage mechanisms, polyamide, fiber volume fraction. Compos B Eng 2017;113:331-41.

[9] Tanaka K, Kitano T, Egami N. Effect of fiber orientation on fatigue crack propagation in short-fiber reinforced plastics. Eng Fract Mech 2014;123:44-58.

[10] Tan KT, Watanabei N, Iwahori Y. X-ray radiography and micro-computed tomography examination of damage characteristics in stitched composites subjected to impact loading. Compos B Eng 2011;42:874-84.

[11] Sola C, Castani B, Michel L, Lachaud F, Delabie A, Mermoz E. Bearing fatigue of composite laminates: damage monitoring and fatigue life prediction. Composites Part B: Engineering 2017;110:487-96.

[12] Cosmi F, Bernasconi A. Micro-ct investigation on fatigue damage evolution in short fibre reinforced polymers. Compos Sci Technol 2013;79:70-6.

[13] Arif MF, Meraghni F, Chemisky Y, Despringre N, Robert G. In situ damage mechanisms investigation of pa66gf30 composite: effect of relative humidity. Composites Part B 2014;58:487-95.

[14] Arif MF, Saintier N, Meraghni F, Fitoussi J, Chemisky Y, Robert G. Multiscale fatigue damage characterization in short glass fiber reinforced polyamide- 66 . Composites Part B 2014;61:55-65.

[15] Rolland H, Saintier N, Robert G. Damage mechanisms in short glass fibre reinforced thermoplastic during in situ microtomography tensile tests. Composites Part B 2016;90:365-77.

[16] Rolland H, Saintier N, Wilson P, Merzeau J, Robert G. In situ X-ray tomography investigation on damage mechanisms in short glass fibre reinforced thermoplastics: effects of fibre orientation and relative humidity. Compos B Eng 2017;109:170-86.

[17] Bretz P, Hertzberg RW, Manson JA. Influence of absorbed moisture on fatigue crack propagation behaviour in polyamides. part 1 macroscopic response. Jounal of materials science 1981;16:2061-9.

[18] Bretz P, Hertzberg RW, Manson JA. Influence of absorbed moisture on fatigue crack propagation behaviour in polyamides. part 2 fractography. Jounal of materials science 1981;16:2070-8.

[19] Pillay Selvum, Vaidya Uday, Janowski Gregg. Effects of moisture and uv exposure on liquid molded carbon fabric reinforced nylon 6 composite laminates. Compos Sci Technol 2009;69:839-46.

[20] Ferreno D, Carrascal I, Ruiz E, Casado JA. Characterisation by means of a finite element model of the influence of moisture content on the mechanical and fracture properties of the polyamide 6 reinforced with short glass fibre. Polym Test 2011;30:420-8.

[21] Launay A, Marco Y, Maitournam MH, Raoult I. Modelling the influence of temperature and relative humidity on the time-dependent mechanical behaviour of a short glass fibre reinforced polyamide. Mech Mater 2013;56:1-10.

[22] Benaarbia A, Chrysochoos A, Robert G. Influence of relative humidity and loading frequency on the pa6.6 cyclic thermomechanical behavior: Part i. mechanical and thermal aspects. Polym Test 2014;40:290-8.

[23] Noda K, Takahara A, Kajiyama T. Fatigue failure mechanisms of short glass-fiber reinforced nylon 66 based on nonlinear dynamic viscoelastic measurement. Polymer 2001;42:5803-11.

[24] Sato N, Kurauchi T, Sato S, Kamigaito O. Mechanism of fracture of short glass fibrereinforced polyamide thermoplastic. Jounal of materials science 1984;19:1145-52.

[25] Sato N, Kurauchi T, Sato S, Kamigaito O. Microfailure behaviour of randomly dispersed short fibre reinforced thermoplastic composites obtained by direct sem observation. Jounal of materials science 1991;26:3891-8.

[26] Selles N, Saintier N, Laiarinandrasana L. Voiding mechanisms in semi-crystalline polyamide 6 during creep tests assessed by damage based constitutive relationships and finite elements calculations. Int J Plast 2016;86:112-27.

[27] Xiong B, Lame O, Chenal JM, Rochas C, Segula R, Vigier G. In-situ saxs study and modeling of the cavitation/crystal-shear competition in semi-crystalline polymers: influence of temperature and microstructure in polyethylene. Polymer 2013;54:5408-18.

[28] Castagnet S, Deburck Y. Relative influence of microstructure and macroscopic triaxiality on cavitation damage in a semi-crystalline polymer. Mater Sci Eng, A 2007;448:56-66. 